\title{
Design of Urban Forests
}

\author{
Simon Bell · Dominique Blom · Maija Rautamäki · Cristina Castel-Branco \\ Alan Simson · Ib Asger Olsen
}

\section{1 \\ Introduction}

Designers work to change the landscape from its current state to one which better meets society's prevailing needs, while protecting the valuable assets handed down from the past and ensuring that the potential for future generations is also maintained.

The urban forest may already contain a great legacy, the best of which must be conserved, restored and maintained. Other areas may need to be altered to a greater or lesser degree, in part to reflect the changes experienced by the community as well as to reflect the evolving urban structure. Significant new areas of urban forest may also be required, possibly to be established on technically difficult sites. Here the designer may have a relatively clean canvas upon which to create a landscape for the future, responsive to current needs but also looking to advance the frontiers of design, especially in meeting the needs of sustainable cities.

Landscapes of woodlands, parks, and trees in streets and other urban spaces take a long time to develop and mature; such landscapes require vision and perseverance on the part of the designers and managers. This vision needs to encompass scales of landscape ranging from the regional planning level where large-scale green structures are designed to unify several urban areas, such as in the English Community Forests or the Dutch Randstadgroenstructuur (Ministerie van VROM 1991) down to the detail of a small park or urban square. It is a tremendous challenge.

This chapter explores the design of the urban forest. Whether the various elements are new to the urban green-space structure, or whether they are existing components which require changes in layout or management due to evolving demands, design has an important part to play. The spatial layout of trees, their composition and structure, interact with the ways people perceive or make use of them and also affect physical and ecological functioning such as shelter, shade and habitat provision.

What are the design elements covered by this chapter and how do they fit together? In Chap. 1 the main focus of this book was set out primarily to include woodlands, parks and street trees. It can sometimes be difficult to be precise about distinguishing between, for example, a park, a woodland, or forest: after all, some places are called 'forest parks'. Street trees obviously include trees in squares and other urban thoroughfares, but what about riversides, canal sides or railways. Where do trees in gardens fit in? These are all part of the urban forest. Some are mainly to be found in the public realm, others in private spaces.

Making the distinction between forest/woodland and park is more complicated in English than it might be in other languages, due to the origins of and historical and cultural associations of these words (Harrison 1992). The term 'forest' originally re- 
ferred to open, wild areas (usually with a high proportion of tree cover), while 'park' meant enclosed (emparked) areas, set aside to protect deer, eventually becoming the kind of landscape parks around country houses and later, city parks. These terms do, of course, change over time and tend to be somewhat fluid. It is also important that the terms reflect the widest possible application across Europe. For the purpose of clarification and structure, the following definitions are used for the rest of this chapter.

Urban woodland means a forested ecosystem of natural, semi-natural or man-made origin, used for a variety of purposes including recreation, nature protection and, in exceptional circumstances, wood production. It is mainly tree covered, although other elements such as water, wet areas, paths and open spaces of different sizes are often to be found. Woodlands may tend to be more multi-purpose than parks and their design may need to accommodate more uses, some of which may conflict while others are complementary (Fig. 6.1). Examples can be found in and around many cities, such as Losiny Ostrov (Elk Island) National Park in Moscow, Helsinki Central Park (Fig. 6.2), the forests around Stuttgart (Fig. 6.3) and Ljubljana, Epping Forest in London or the Vienna Woods, all original forests absorbed into the city. More recently created examples include the Vestskoven (West Forest) on the edge of Copenhagen and the Amsterdamse Bos, near Amsterdam.

Woodlands may also be more dynamic, changing in layout and structure over time. Many people may consider them to be more wild or natural in character than other elements of the urban forest and this quality needs to be considered in design.

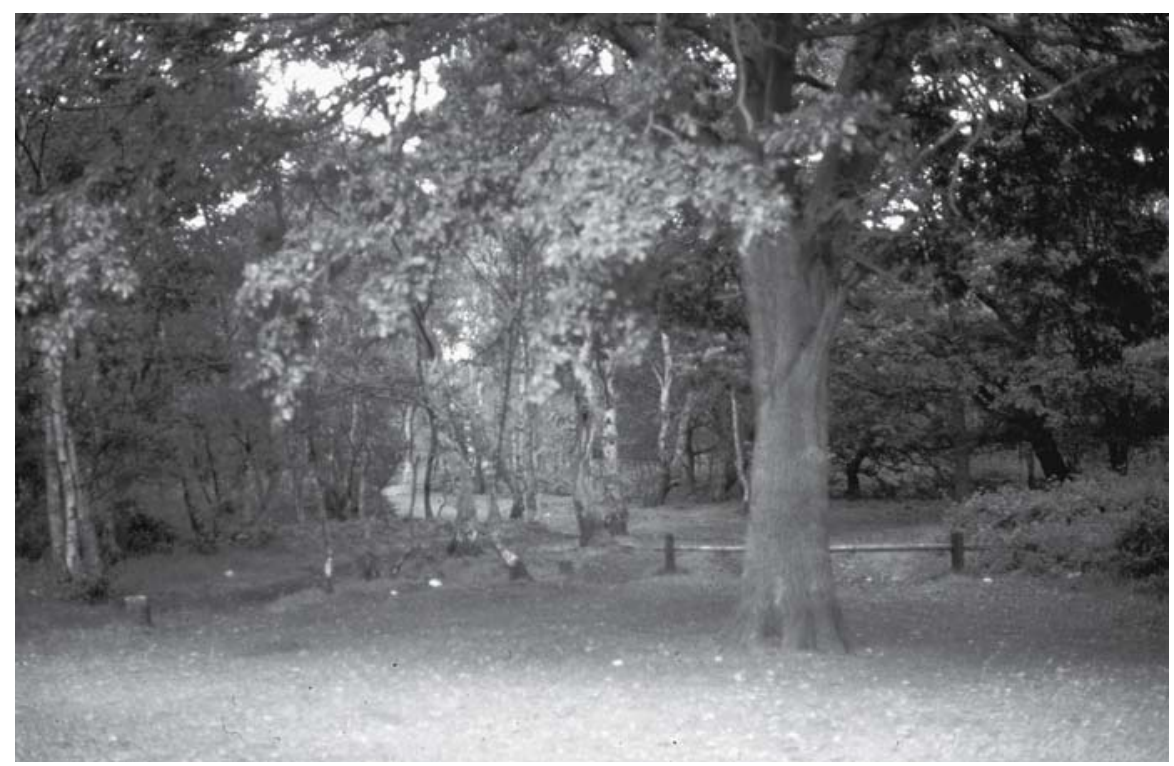

Fig. 6.1. This is a woodland at Sutton Park in Sutton Coldfield near Birmingham in Britain. Many people use this woodland for dog walking, getting fresh air and exercise, and playing impromptu games in summer. People in Britain are not always used to visiting woodlands, which occupy only a small part of the landscape. Shelter from cold winds is important (photo: S. Bell) 


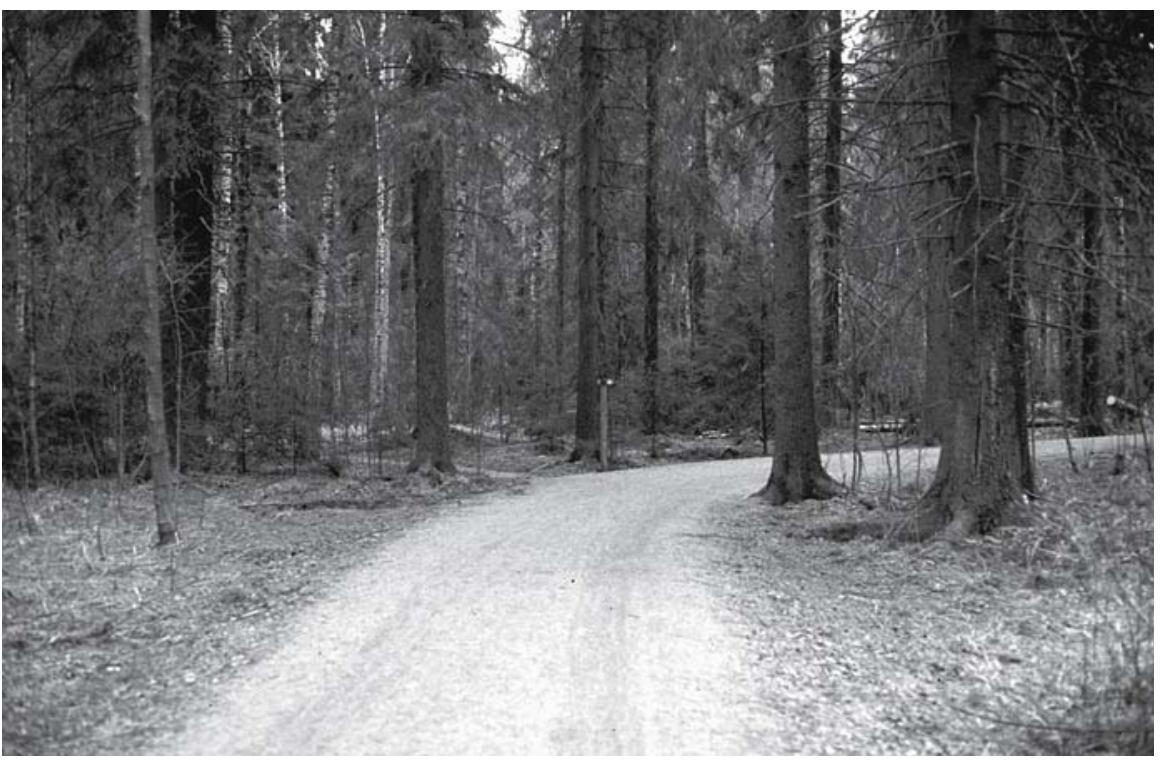

Fig. 6.2. Helsinki city forest (Central Park) is mainly a forest of native trees, spruce, pine and birch. It is used for similar activities as the British example except that in the long, dark winter there is much more skiing. People in Finland are very fond of forests, which cover much of the country (photo: S. Bell)

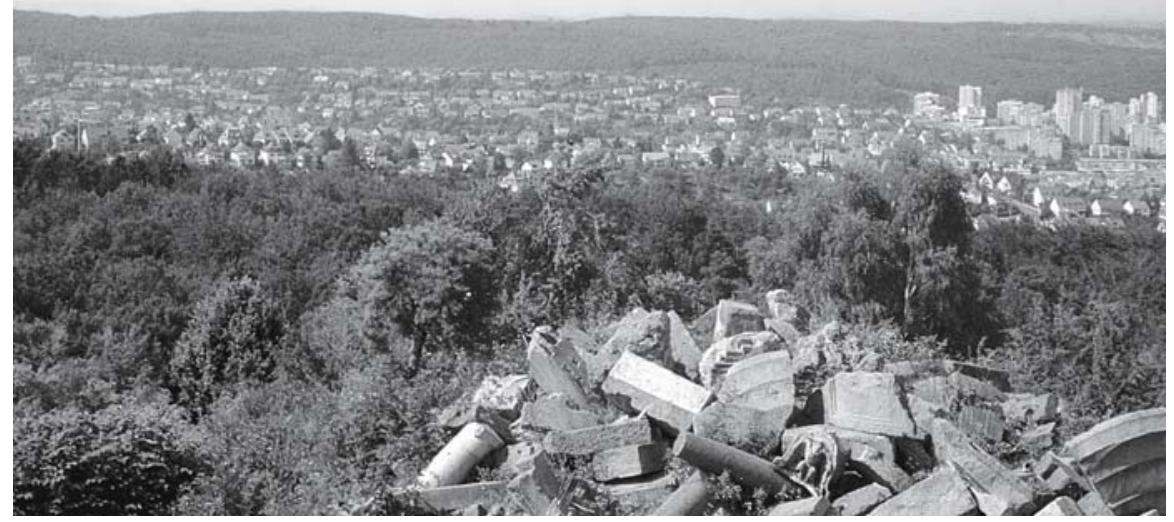

Fig. 6.3. Stuttgart, in Germany, has extensive forest around the suburbs, much of which is available for recreational use. The continental climate of central Europe means that forests help to keep visitors cool in the hot summers and comfortable during the cold winters (photo: S. Bell) 
A park is a mainly open space set aside for recreational purposes, both formal and informal, with a significant component of trees to provide visual screening, shelter, shade and aesthetic pleasure (Fig. 6.4). As well as trees, grass is likely to be a major vegetation element together with shrubs, water, surfaced areas such as roads and paths and possibly buildings and other structures provided as amenities for the public. Famous examples of old deer parks that have become city parks include Jaegersborg Dyrehaven in Copenhagen and Sutton Park near Birmingham.

Existing parks often reflect the design movements or styles that prevailed at the time they were designed. These may be national styles, such as the 'English style' or international, such as the Modern Movement. Well-known examples of parks in different styles are Phoenix Park in Dublin, in the English style, the Boboli Gardens in Florence in a Renaissance style, Versailles near Paris in the unique $17^{\text {th }}$ Century French style, or Parc La Villette, a Modern (or post-modern) park, also in Paris (Jellicoe and Jellicoe 1995).

Street trees are planted and maintained in the public spaces within housing areas, between buildings within the urban fabric, along the constructed type of edges of rivers and canals and around lakes, squares, along streets, avenues and boulevards and in association with old linear fortifications. They complement the architecture of the urban area. Such locations may present challenges to the designer because of the practical constraints that often apply. Cities well known for their street trees include The Hague, London (with the famous London plane tree) and Paris with its shady boulevards.

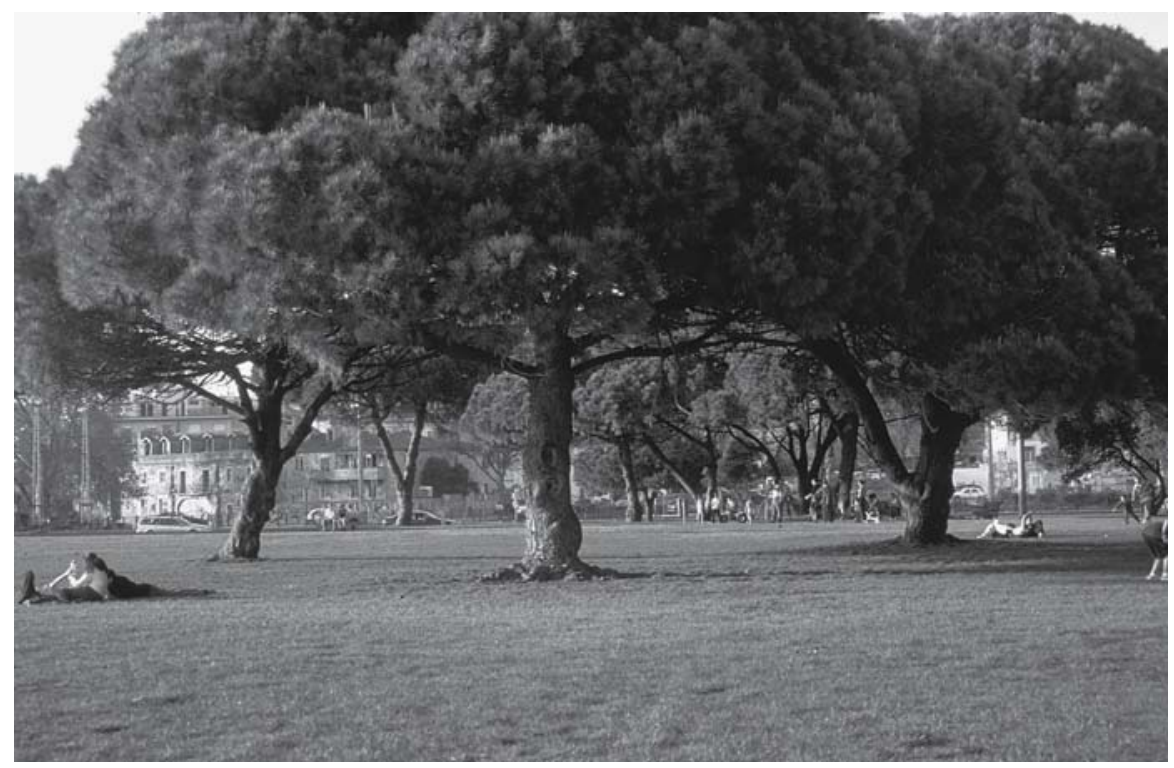

Fig. 6.4. In Lisbon, this park is characterized by the canopy provided by the trees which gives a shady place for activities which, while similar to elsewhere, need more shade in the long hot summer, although they can take place comfortably for much more of the year owing to the milder Mediterranean winter (photo: C. Castel-Branco) 
Trees can also be important features of private or commercial spaces such as gardens or business premises. As such they may represent a significant proportion of the tree population of a town or city. On the one hand it is difficult to control how trees on private property are used as part of a wider, unified urban design but, on the other hand, they represent a chance for people to express themselves and to develop their own, personal relationships with trees and plants. However, it is important not to lose sight of the need for an overall, city-wide sense of unity in the complete pattern of urban woods, parks, street trees and trees in private spaces.

Often one urban forest element leads into, is connected by or visually links with another to present an overall sense of a city-wide forest. This coherent pattern should be developed strategically, taking the existing elements and planning new ones to fill gaps and establish new connections. It is highly desirable that a city resident can encounter a tree outside their door and through this, feel a connection to the wider urban green-space system, if not the wider landscape beyond (Bell 1994, 1999b).

\section{Chapter Objective}

The objective of this chapter is to present an overview of the main issues, concepts and principles concerning urban forest design. The chapter mainly covers the design of trees in public spaces, because this is where the large scale is relevant and where the public benefits are mostly achieved. The design concepts and principles are, however also relevant to the design of private and commercial spaces. Since other chapters of the book deal with many of the physical and ecological benefits of urban forests (e.g., Chap. 4) this chapter will concentrate on the social, experiential and functional aspects associated with people making use of urban woods, parks and street trees.

Urban forestry is a multi-disciplinary subject and this chapter on urban forest design can only deal relatively superficially with a wide range of aspects that form disciplines in their own right, such as forest landscape design, urban park design, urban design, arboriculture or habitat creation. The references listed at the end of the chapter provide a sample covering this diverse, multi-faceted subject.

The chapter is arranged into five main sections. Firstly, the European dimension is presented, reflecting the fact that urban forest design has to relate to very different circumstances around Europe. Secondly, a brief historical review looks at some of the past design aspects that form the legacy found today. Thirdly, a number of main conceptual themes are explored in relation to various design dimensions: social, experiential, functional and ecological. Fourthly, design concepts examine the main approaches to urban forest design found, through practice, to be most successful. Fifthly, design considerations describe the process of design and the detailed aspects that have to be considered under different circumstances. Finally, the chapter considers what opportunities exist for designing the urban forest of the future.

This chapter has been written by a group of experts and it is based largely on their combined experience. The chapter presents a combination of tried and tested approaches together with new visions and ideas for the future. Readers should be able to feel comfortable with most of the concepts and, hopefully, to use them to create wonderful new landscapes. 


\section{2}

\section{The European Dimension}

When considering urban forest design across Europe, it is important to ensure that regional differences are highlighted. The character and function of urban woods, parks and trees contain both similarities and differences between, for example, London, Helsinki, Vienna and Florence. People undertake popular activities such as dog walking or jogging, picnicking or kicking a ball about in all four cities. However, the climate, the ecosystem, the cultural history and the character of the people of each country also lead to major differences and it would be inappropriate and undesirable to recommend principles of design that ignore this rich variety.

Between the European-wide and the national or local scales it is possible to detect broad regional characteristics of what might be termed 'forest culture' (Sims and Hislop 1999). These zones, shown on Fig. 6.5, reflect the climatic and ecological differences, the importance of forests in the national economy and as part of the landscape, and the way forests and trees relate to the national culture through traditional uses, forms of recreation, folktales and legends.

The northern forest culture covers Norway, most of Sweden, Finland and the Baltic states. Here the forest is a major element of the landscape, the national economy and in the everyday lives of the people. Cities such as Stockholm, Oslo, Helsinki, Tallinn, Riga or Vilnius, tend to be set within and surrounded by large tracts of forest, which expand beyond the urban boundary. The cities have expanded into the forests and the people go out into them almost as much for mushroom and berry picking as for walking or skiing (Sievänen 2001).

The central European forest culture covers those countries with a mainly continental climate but with milder winters and warmer summers than the northern countries. The landscapes are quite forested but not so heavily as in the north, and the woods

Fig. 6.5.

This map shows the division of Europe into four different zones of 'forest culture'. This regional variation should be taken into account in the design of the urban forest (illustration: S. Bell)

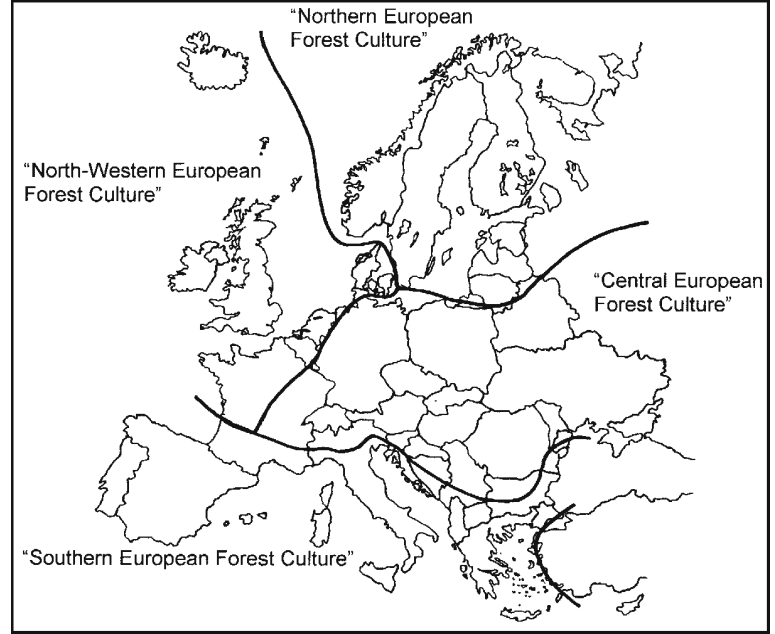


contain a higher proportion of broadleaf plants and are well managed. Many cities, such as Stuttgart or Vienna possess significant wooded tracts but these lie mainly at the periphery and may be former royal or aristocratic hunting estates with a long history of management and use. The people of the cities use these woods intensively for all kinds of recreation and the woods may be under considerable pressure.

The southern forest culture occurs in the mainly Mediterranean countries, including southern France and Portugal. The Mediterranean climate of hot summers and warm winters means that people live outdoors for a lot of the time, so that street trees, parks, squares and woodlands provide much needed shade. Forests may be significant in mountainous or hilly parts. Close to cities most forests were once reserved as hunting parks and are now used for recreation. In these countries the urban culture has grown apart from the forest culture. Fire is a major threat to forests with a high degree of public use (see also Chap. 11).

The north-western forest culture includes Britain, Ireland, Belgium, the Netherlands, Denmark, southern Sweden, north-east France and Iceland. The common factor in these areas is the loss of most of their forest cover over the last 3-4 thousand years, so that forests now occupy a small percentage of the land area. Many forests are now of plantation origin and are intensively used. In popular culture forests are sometimes seen as alien places, so that urban people are less spiritually connected to them than in the Northern zone, for example. These are also highly urbanized and industrialized countries with dense populations who need space for recreation, but where private land is not always available for public access.

\section{3}

\section{A Historical Review}

\subsection{1}

\section{Development of Urban Forests}

Chapter 2 explores the historical background to urban forests in some detail. However, from a design point of view it is worth noting some major features that continue to have an effect. These form not only a historical legacy of trees in towns and cities but continue to have an influence on urban design.

In Europe, as opposed to North America, cities are often very much older and possess different features. For example, the core areas of many major cities are of medieval origin, with narrow winding streets and they developed 'organically' (Jellicoe and Jellicoe 1995; Bell 1999a). Trees and parks rarely form a significant component of these cities, although, as the cities expanded beyond the lines of walls or fortifications, these redundant defences often became parks close to the old centers. The boulevard rings of Moscow or Riga or the old defences of Copenhagen or walls of Lucca (Fig. 6.6) are examples of this. The outer areas of these cities, as well as many more modern city developments, were often planned and laid out with a structure of avenues, tree lined streets, formal squares and parks designed not only to enhance the city architecture but also to provide aesthetic and public health functions. These often reflect the pre- 


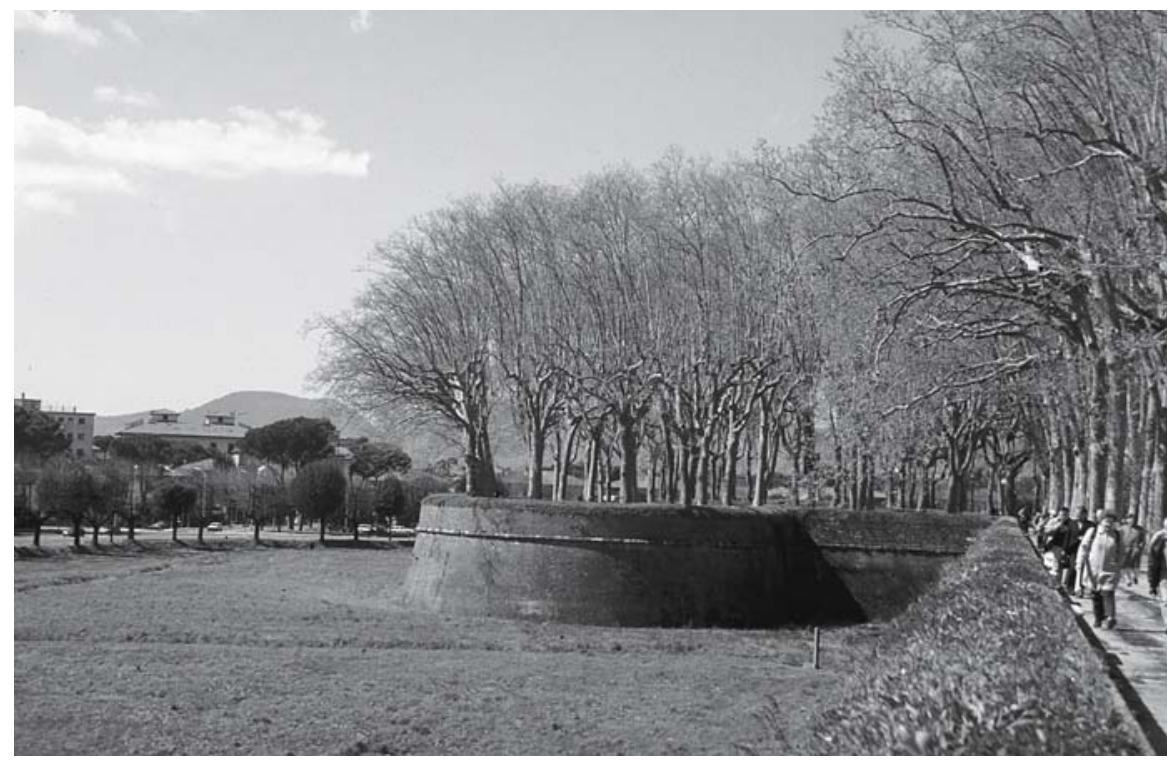

Fig. 6.6. The old city walls of Lucca, in Italy, had trees planted on them to help dry out the earth fill and make them stronger fortifications. Their defensive purpose has long ceased to exist, so that they make a very attractive, shady walk right around the old city (photo: S. Bell)

vailing style of the different eras in which they were laid out. The New Town of Edinburgh, the $19^{\text {th }}$ century expansion of Barcelona and the English New Towns such as Milton Keynes reflect this approach (Bell 1999a).

As many cities expanded they incorporated already existing parks and forests (Fig. 6.7). Sometimes forest areas remain in their natural state, although subject to increased pressures, others have been modified, either through management or as a result of human use. The idea of parkways or greenbelts surrounding the dense urban area became a design concept where urban forests influenced the urban growth. Helsinki has gradually expanded into the surrounding forest areas and Tapio New Town in Finland was designed to fit into the forest into which it was built. Sometimes the expansion of cities has brought threats, for example the problem of fire in Mediterranean forests close to cities such as Thessaloniki in Greece.

Many post-war city developments right across Europe have been built for mass housing with dense populations living in high or medium rise apartment blocks. Access to green space has often been at a premium but it has not always been either readily available or designed to a good standard, despite the best intentions when they were constructed (Fairbrother 1970). Many of the open spaces around housing blocks, whether in Glasgow or Moscow can be depressing because of the lack of good green structure. Conversely, there have been many examples of ambitious new urban forest programs and developments, those of Amsterdam and other cities in the Netherlands, from the 1930s, Copenhagen, in Denmark, from the 1960 s and around a number of cities and towns in the UK over the last 10 years or so being some of the most significant. Public participation in planning, design and management is also increasingly important and will influence design more and more (see Chap. 8). 
Fig. 6.7.

This piece of urban forest in St. Petersburg used to be well outside the city, but as massive housing development took place after the war, it has become surrounded by the city. From a woodland managed to provide timber it has become a recreational amenity, with implications for its layout and management (photo: S. Bell)

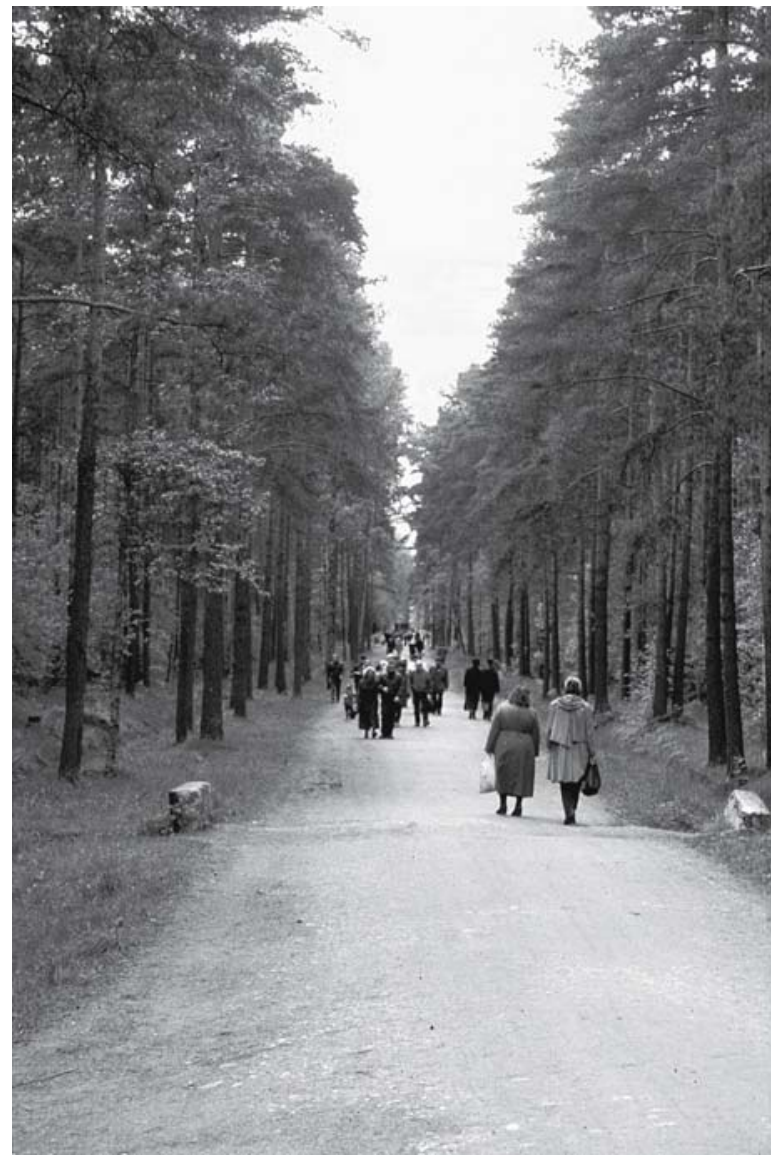

\subsection{2}

\section{Changing Perceptions, Uses and Management}

Urban society is constantly changing and developing, placing new demands on the urban forest. Designs that fulfilled the needs of society 300,200 or 50 years ago do not necessarily satisfy today's requirements. Designers need to be able to maintain important elements of tradition and cultural heritage contained in the existing resource, whilst at the same time enable it to be managed for changing use patterns. The urban forest takes time to grow: woods planted 10 years ago are only now developing much of a structure; by the time they are mature new demands are certain to be placed upon them (Hodge 1995).

Design is a constant process and should be an integral part of management, so that the developing landscape can change and evolve to meet new challenges. Designers therefore need to seek for universal elements that withstand these changing pressures. One approach, as far as woodland is concerned, is to keep as close to nature as possible and not to become too associated with design styles that quickly go out of fashion as 
opposed to the long-lasting forest atmosphere. Designers should also use natural processes as the base to prepare the space for human use. The continuity over time of a woodland ecosystem also has important spiritual and aesthetic values that more ephemeral elements lack. This should be considered together with the economic, cultural and social processes driving design and does not mean that the early years of establishment are left entirely to natural processes. Instead, natural processes are fitted into management to produce the design. Having said that, it is also important to develop new ideas and to look forward as well as back.

\section{4}

\section{Main Conceptual Themes}

When considering the design of the urban forest, whether street trees, parks or woodlands there are some key conceptual themes to be considered. These are presented as four interlocking dimensions. Any over-emphasis on one dimension to the exclusion of others may cause an imbalance in the design, although in the case of particular projects some dimensions are likely to be more important than others. These dimensions are

1. the social

2. the experiential

3. the functional

4. the ecological

Of course, since these dimensions interlock they have to be considered in an integrated way, rather than as separate, independent aspects. Thus, the interpretation and application of each dimension will be unique to the location, setting and social and cultural context.

\subsection{1}

\section{The Social Dimension}

Social functions of the urban forest are many and varied, generally including those aspects where the social life of people as individuals or in groups can be enhanced. To some people urban life, as a result of their living conditions, might be considered to be a negative experience, so that access to green areas is considered to be an escape. Others might see little distinction between the built and the green environment, considering them both to be equal parts of the urban area, using both components in an integrated way to obtain a high quality of life. This means that the aspects of the social dimension, escape, social activities, and safety and security, need to be considered in the context of the wider social and urban environment.

\section{Escape}

In all areas of Europe and especially in the larger cities, where the built environment is the dominant medium of most peoples' lives, a major social benefit is being able to 
escape from the urban scene from time to time and enjoy solitude or company in a more relaxed atmosphere conducive to reflection, conversation and stress reduction (Bell 1997a, 1999b). This is not to imply that urban life is wholly negative but that part of what contributes to positive urban life is the chance to experience the contrast with the built environment provided by nature. Street trees provide a valuable presence of nature and, en masse, can present a significant foil to buildings and other constructed features. Parks with a strong component of trees that screen out the sight of buildings provide valuable oases within the city. It is, however, woodland that provides the strongest sense of separation. This is because the mass of trees and the effect of their height can create an inward looking landscape, a separate world, where the visible and audible reminders of the external landscape can be blocked out and the constant, inescapable stimulation to the senses, which can be one of the negative aspects of an urban setting, replaced by the calming and harmonious exposure to nature (Bell 1999c, Fig. 6.8).

Thus, if the function of a park or woodland is to provide the opportunity to feel a 'psychic distance' from the urban scene, a style or approach to design that maintains, enhances or creates an impression of naturalness or wildness may be preferable to a more formal approach. However, it is important to allow for cultural references to be incorporated and to develop a sense of place that helps people to identify more strongly with their community. People living in cities in northern Europe, who feel closer to the forest, may need to be able to escape from the built environment more than those from southern Europe where the tradition of city living is more deeply rooted.

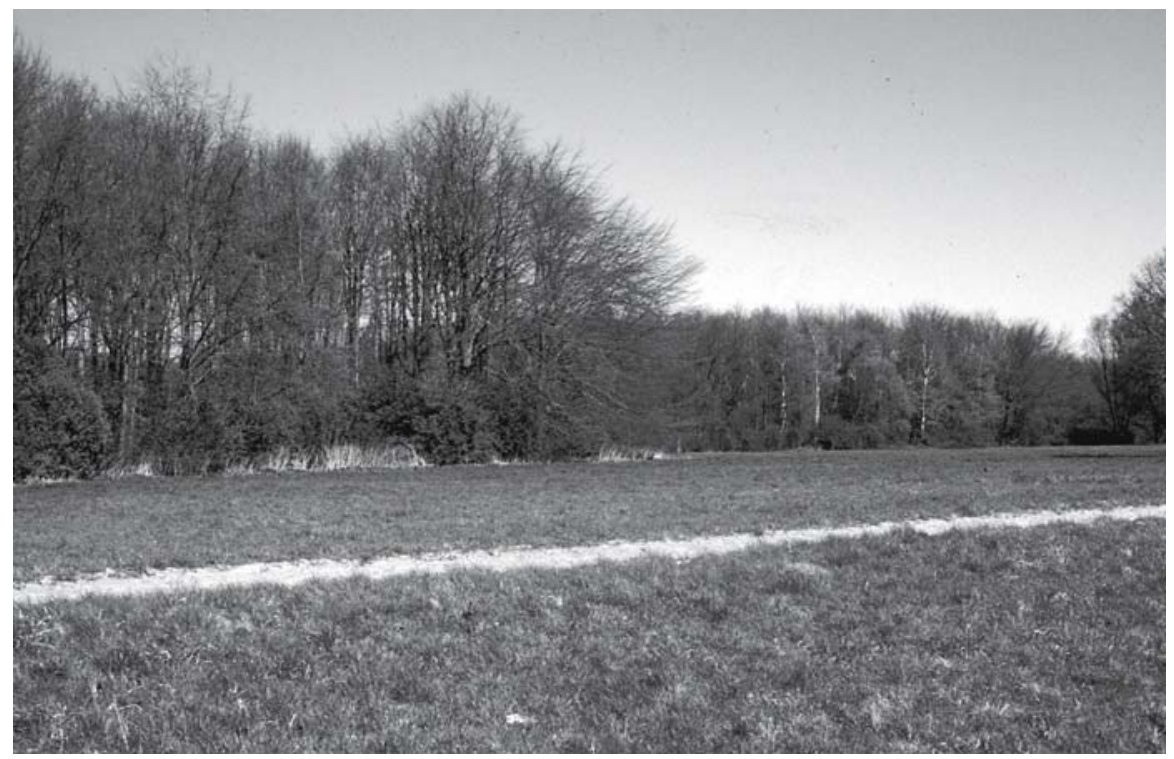

Fig. 6.8. When visiting the Amsterdamse Bos (city forest of Amsterdam) it is possible to shut out most of the visible signs of the surrounding urbanized landscape. Unfortunately, it is not possible to remove the sound of aircraft approaching or leaving the nearby Schiphol International Airport (photo: S. Bell) 


\section{Social Activities}

Parks and woodlands provide the setting for many social activities, for example walking, sitting looking at the view, having a picnic, kicking a ball around, skiing, orienteering, for social intercourse with family or friends and so on. Some of these can take place in fairly gregarious conditions in a small space. Others require a bigger area and sufficient space to gain a sense of solitude. There is also the potential of streets, parks and woodlands to provide a neutral place (not owned or controlled by any one social group) where the integration of various ethnic, social or other groups can take place, thus reinforcing community integration. Squares shaded by trees are another example of a setting for social activities within cities, such as those in southern Europe, where more of life takes place out of doors than in the north.

The use of the urban forest by children is an especially important social use. Children who form associations with the natural world and who visit and play in woods and parks are much more likely to continue to do so as adults (Ward Thompson et al. 2002). The role of urban green places for play and the value that natural areas provide over more urban playgrounds is widely recognised and should be maximized (Bell 1997a).

\section{Safety and Security}

A practical aspect of the development of opportunities for social interaction in urban parks and woodlands, as well as on city streets, is the sense of safety and comfort experienced by visitors (Schuit and Hajonides 1991; Burgess 1995). In the northern and central European forest culture areas the population is generally more comfortable with visiting woods and forest parks. They are less worried about being attacked or getting lost. People of the north-western and southern forest culture may be less comfortable and need an atmosphere that reassures them. This may include greater visibility along paths and beneath trees and more obvious signs of a management presence and clear signposting. Conversely, it can be valuable to allow certain places to develop a wilder character, less easy to enter and perhaps more exciting, to cater for the people who prefer to find solitude, who wish to be self-reliant and who are not fearful of being in wild places (Bell 1994). Trees in streets and squares may attract people to use these spaces more and with this increased presence of people may come a greater sense of safety and security.

Safety issues also include physical safety and the worry, especially by elderly or disabled people, that they may hurt themselves. Accessibility to as wide a range of potential users as possible is also an important feature in the design and layout of paths, especially in hilly areas (Bell 1997a).

\section{4 .2}

\section{The Experiential Dimension}

The urban forest provides opportunities for many experiences, like different aesthetic qualities presented through different design styles, and the role of the urban forest in urban life. 


\section{Aesthetics}

Parks and especially woods provide opportunities for a rich aesthetic experience that is different from and contrasts with that of the built environment. In the fast changing urban scene, novelty and fashion are often the dominating aesthetic influence. In a forest park or deep in a woodland, the richer and more profound multi-sensory experience possesses a timeless as opposed to an ephemeral quality. In woodland, a harmonious blend of sights, sounds, smells, tastes and the full range of haptic or kinaesthetic stimuli are present. This can provide a rewarding contrast, where urban streets are counterpoised by the park or forest, enhancing both experiences. With the seasons these changes also present continuity (Berleant 1992; Bell 1999a). The full aesthetic engagement of all the senses works at a deeper level, for example the sense of time associated with large old trees that have been there for centuries or the connection of death and decay with new life and growth (Bosch and Slabbers 1993). These are features that enrich us and connect us with nature.

The aesthetic experience of urban centers is often enriched by the presence of trees in streets, squares and gardens. They can bring seasonal changes close to people and the sight of nature close to home can be very rewarding. Contrasts between built and natural forms also provide an aesthetic stimulus.

\section{Design Style}

The question of aesthetics is inevitably connected with style. Woods and parks take many years to plan and plant as well as to develop and mature and are at their best several decades or even centuries after they were first planned. Thus, if a particularly trendy style has been adopted it will be out of fashion well before the landscape has reached its prime. However, it is impossible and undesirable to eliminate all traces of contemporary design influences since these are, inevitably, applied unconsciously by the designer who was trained in a particular era. Furthermore, it is appropriate for there to be some references to the period in which the park or woodland was designed since these will reflect the current social and cultural norms. In this way they will contribute to the fabric of the city, which already reflects all eras of its development, and to the overall cultural heritage of the future.

Trees in streets and squares contribute much to the overall urban fabric and can be used as part of a contemporary design. Their use in such designs can involve the selection of tree form and also their management as individual and groups of trees. Many older examples reflect past architectural and design styles and the current and future trends are also likely to be represented.

The layout and design or style of places such as parks or woodlands, the paths, planting patterns and open spaces, can act as symbols for the degree of control or active presence of people that can have implications for the experiences available to people. For example, a woodland laid out and managed so as to present an impression of naturalness (the absence of geometry, formality, urban forms and materials etc.) can send a symbolic message to the visitor - that he or she is close to nature and away from too much control over the landscape. This can be contrasted with a woodland laid out in a formal way with avenues, allées, 'rond-points' and other features and where paths are surfaced in tarmac, trees planted in straight lines and so forth (Forestry Commission 1992). 
The Role of the Urban Forest in Urban Life

Trees in streets, squares and smaller spaces within the denser parts of cities enhance everyday life while larger parks and woods cater for the non-urban experience. As a sense of continuity and timelessness is needed in design to counteract the rapid changes in the urban scene, there is no better template for this than nature, in the sense of natural processes of vegetation growth and development. Furthermore, it can be argued that the urban forest acts as a kind of intermediate landscape, a stepping-stone between the built city and nature. The experience of a single tree in a garden or street, which is itself part of a larger urban forest, can provide that link, via the park, to the urban woodland, which, if well designed, can symbolize pure, idealized nature (Bell 1994, 1999b).

\subsection{3}

\section{The Functional Dimension}

Street trees, parks and woodlands carry out a range of functions, many of which are covered by other chapters. The functional aspects discussed here include accessibility, promotion of health and well-being, the need to provide for a wide range of types of physical exercise (carrying capacity) and the effect of different climatic conditions.

\section{Accessibility}

Urban woodlands and parks, as well as other open spaces, must be accessible to as much of the population as possible. This includes people with a wide range of physical or mental disabilities, elderly people, young children, people from different ethnic groups and poorer people. There are specific design requirements for many of these categories, but it is important not to spoil the desirable aesthetic qualities of the park, woodland or other space when increasing access provision, otherwise the experiences, which are as important to all these groups, will be diminished (Bell 1997a).

Different activities have different design requirements. For example, paths used by pedestrians, bicycles or horses are laid out differently with different widths, surfaces and headroom. The dimensions, gradients and other features needed for inclusive access must also be considered within the constraints imposed by the terrain and landscape character.

\section{Carrying Capacity}

Sites have to be designed to satisfy both physical and visual carrying capacity. For example, a heavily used park may suffer serious soil and vegetation erosion from too many feet. More robust surfacing and control of access would increase its physical carrying capacity. A straight path or avenue means that everyone using it is visible at once, so if it is busy it has a low visual carrying capacity (Forestry Commission 1991). A winding path among trees and shrubs means that it is only possible to see much shorter distances, so that most users of the path cannot be seen, even though there may be more of them. This increases the visual carrying capacity (Fig. 6.9). 


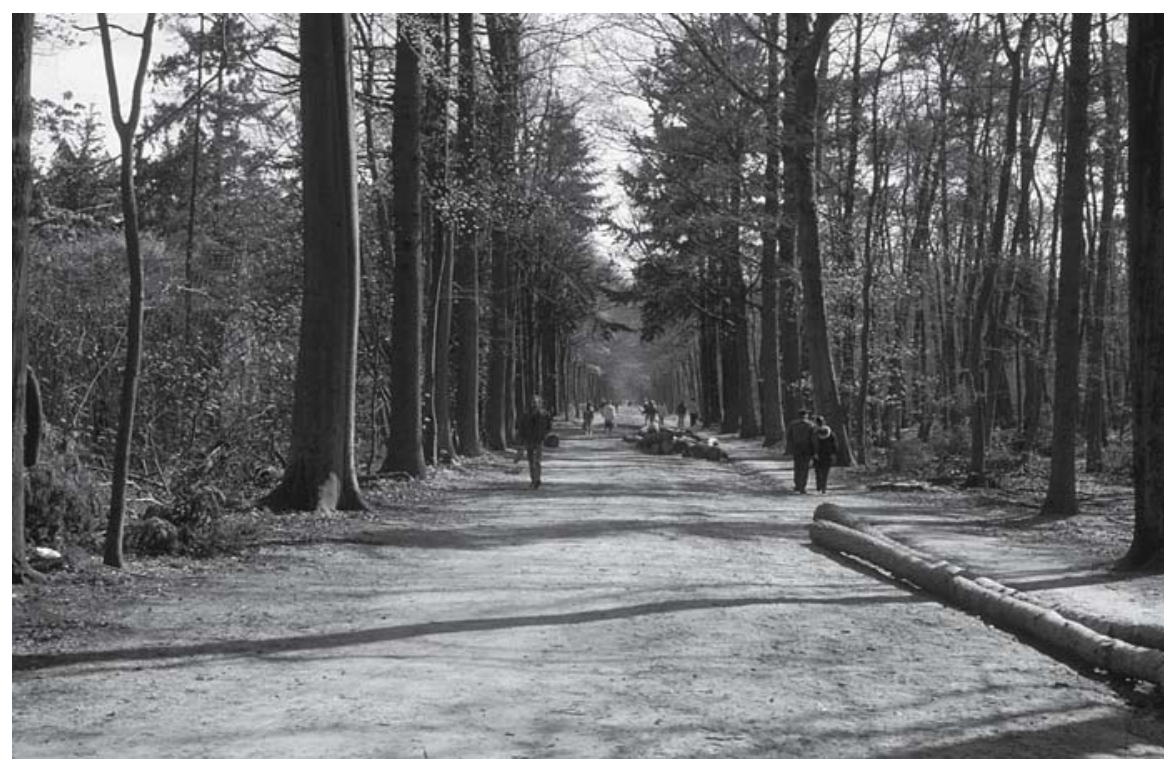

Fig. 6.9. This former royal hunting forest, at Breda in the Netherlands, retains its formal layout of straight 'rides' or avenues. While reflecting the historical character and cultural history, this layout does not have as high a visual carrying capacity as more 'naturalistic' approaches to design (photo: S. Bell)

Experience has shown that physical and visual carrying capacity generally increases at a proportionally greater rate than an increase in area (Forestry Commission 1991). Thus the functional potential is more than double for an area twice the size. This has implications for both the pressures on small, isolated areas and the desirability of acquiring land areas that are as large as possible.

\section{Climate}

There are also climatic differences across Europe that need to be reflected in the design. For example a picnic or sitting area in a Mediterranean country probably requires a degree of shade, whilst in northern Europe the sunniest places will be chosen or, in windy areas, shelter might be the most important. Trees help to moderate extremes of climate and weather all year round in any country, for example by reducing windiness near buildings, decreasing the wind-chill factor, increasing cooling in summer and the reduction of glare or mitigating the impact of rain or freezing conditions. Thus, woodlands in particular with the greater tree cover, offer the possibilities of all-year-round use, ideal for those who enjoy the outdoors as part of their daily routine.

\subsection{4}

\section{The Ecological Dimension}

The four European regional forest cultural types described earlier are all generally based on climatic and ecological differences. The conservation and development of 
biodiversity is one important goal of urban forests despite the great social and economic pressures present. This is a major challenge for design. It is usually important to reflect the local ecological characteristics of the areas where the woodland, park or street trees are to be located. However, there are some challenges.

\section{Urban Ecology}

Many cities present a significantly altered ecosystem. In part this is due to the local microclimate change inherent in a built environment and also due to the large-scale introduction of exotic plant species in parks and gardens. In many instances there is abandoned land which becomes taken over by scrub woodland composed of an ad hoc range of plant species. Moreover, disturbed land from former industrial use such as coal mining or gravel extraction may lack soil or contain trace minerals or chemicals which inhibit plant growth, have impeded drainage or produce noxious gases such as methane (Moffat and McNeil 1994). All these influences may limit the ecological possibilities. On the other hand, urban forest planting can help to improve or revitalize the natural capital of an urban area through the increase of ground water infiltration, soil amelioration, or erosion control.

In cities where the urban development has expanded into or around woodland there is more scope to retain the natural processes and plant composition and structure, although climatic or drainage change and the impact of people using an area may inevitably alter it. Even quite small natural patches can be successfully retained. There is also scope to create new habitats or to promote natural processes that ultimately lead to the development of new habitats.

\section{Landscape Ecological Principles}

Landscape ecological principles should be employed as a key part of the design process, employing devices such as linking corridors to connect scattered habitat fragments and allow wildlife species to move from one to another (McHarg 1969; Forman and Godron 1986; Gustavsson and Ingelög 1994; Forman 1995; Komulainen 1995). It is important to design and manage the woodlands according to the natural conditions which give different potential and inherent habitat diversity to the site, although this may be difficult where the ground and soil have been disturbed. These approaches may have considerable impact on the design style when compared with more traditional urban parks, for example.

In urban areas there are possibilities to develop the ecological values at several different scales:

1. The regional scale: here the green area of a town or city can be linked into that of a wider region by maintaining or developing strong connections. Peri-urban woodland connected to the landscape structure of the rural hinterland can be very effective, while corridors extending into the urban areas from the peri-urban woodlands develop the connections further (Marsh 1991).

2. The city scale: there are opportunities to develop a green network within an urban area, connecting parks and woods via linear corridors, the use of street trees and also gardens (Tummers and Tummers-Zuurmond 1997). Trees can provide the connecting matrix with which patches of different habitats can fit and be linked to one another. 
3. The habitat scale: a variety of habitats can be created and protected, many of which are not necessarily natural; in fact many habitats can be artificially created quite successfully in urban areas and be very valuable ecologically and educationally. Wooded areas can incorporate wetlands, ponds, grassy spaces and a variety of edge habitats. Parks can include ponds, which are important for birds as well as providing the chance for people to experience wildlife close at hand (Baines and Smart 1991).

The social value of nature to urban people should not be underestimated, and the ways of developing a strong ecological basis for the urban forest should include the possibilities for people to get close to nature as part of their everyday lives. This also needs to be considered in design (Coles and Bussey 2000).

\section{5}

\section{Design Concepts}

This section explores a number of key design concepts, which have been mainly developed through practical experience over many years, supported by a degree of research. There remains plenty of scope for designers to take these concepts and to develop them further.

\subsection{1}

\section{Woodland}

In order to satisfy the four dimensions described above, woodlands, whether existing or newly created, should generally embody the concepts of 'nature in the city' and 'composition and structure'.

\section{Nature in the City}

Woodland usually represents the archetypal 'natural' or 'permanent' landscape and should present opportunities for people to escape the pressures of the city by providing a natural or naturalistic ambience (Bell 1994, 1999b). Woods should enclose the visitor and screen the visual reminders of the city from view whilst at the same time avoiding creating an impression that frightens people (especially in the area of the north-western and southern forest culture). It may also be desirable to allow some views out of the woodland towards key city landmarks, in order to balance the idea of cutting people off from the city with a sense of place and orientation (Laurie 1979, Fig. 6.10).

\section{Composition and Structure}

Woods should contain the range of tree, shrub and other plant species and compositional patterns and layers found in natural woodland, as these produce more biodiversity values and are easier to manage and maintain. The matrix or structure of woodland should contain a range of open spaces but if these exceed around $30 \%$ of the area there is a risk that the sense of enclosure will be lost (Forestry Commission 1991). These open spaces may include different habitats and spaces for recreational and social activities. Linear spaces 


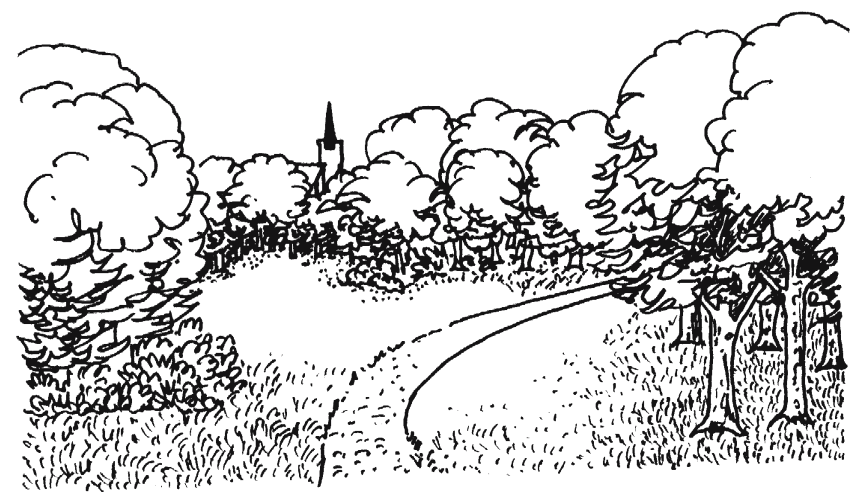

Fig. 6.10. This sketch shows a path leading through an open space in a woodland. The path winds among the trees, creating a sense of mystery. While generally maintaining a sense of enclosure, screening out the sight of the city, glimpses of key landmarks, such as a church spire, have also been retained. This gives reassurance and orientation to visitors. The trees include multi-layered stands with graded edges, better for wildlife, and also open stands with no undergrowth, to allow views through the trees (illustration: S. Bell)

Fig. 6.11.

This diagram shows a woodland within which are several open spaces. These include a children's play area near to houses, some archaeological remains and a pond, wetland and stream complex. These are connected by footpaths, along which there are some linear open spaces. Open space has also been designed around the perimeter of the woodland next to housing so as to avoid the effects of shading (illustration: S. Bell)

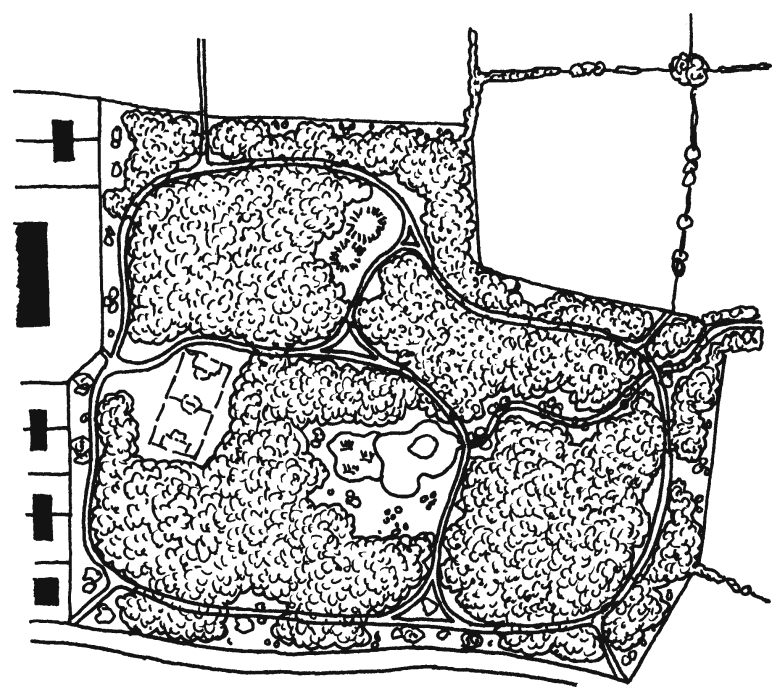

can be used to link nodes of larger scale open space. The main open spaces are usually located towards the edges of larger woodland areas nearer to the city, for ease of access and to emphasize the gradation of managed to wilder landscape (Fig. 6.11).

Within the range of possible structure and composition there are opportunities to manage woodland to create different atmospheres, or situations of greater safety. For example, simple structures that can easily be seen through might be used in some places while multi-layered, more complex ones might be used to create a wilder feel and a stand of more use to wildlife. Stands of single species can be contrasted with ones of mixed species. Stand conditions change with age, so while younger stands may be dense they may become less dense and more open as they mature and as various manage- 
ment activities take place. There is a lot of scope for design within the range of composition and structures found in natural or traditionally managed woodlands as well as the potential to develop new models to suit a particular purpose (Forestry Commission 1992; Gustavsson and Ingelög 1994; Gustavsson 2002).

Woodland design is accomplished through the manipulation of the spatial pattern of different stands of trees, their species composition and vertical structure. Edges are also very important. These elements are manipulated through woodland management and the adoption of different silvicultural systems (Komulainen 1995; Sarlov-Herlin and Fry 2000). Species selection can be based on the sole use of native species, or a mixture of native and introduced, depending on the design objective, site, climate or ecological value. There are often distinct regional variations, where, for example, woodlands in the northwestern zone may contain more introduced species for a variety of historical reasons, while the north European zone is almost wholly confined to the use of native species.

\subsection{2}

\section{Trees in Parks}

Parks, according to the definition given earlier, tend to consist of open spaces where trees provide mass and structure and define the character and scale of space. Trees may be dense and block views or more widely spaced and open so that the space/mass junction is blurred. It is the designer's job to control and manipulate the space/mass structure and relate it to the social, aesthetic, functional and ecological dimensions (Laurie 1979; St. Bodfan Gruffydd 1987; Bradshaw et al. 1995).

Much social activity in parks takes place along edges, where people can temporarily create personal space (Bell 1997a). The length of edges (often wooded areas, tree clumps, shrubs or hedges) and scale or variety of shape determines to some extent the capacity of use. Composing views, vistas and using coalescing groups or clumps of trees to make the size of the area appear larger is also a useful device. Imparting a sense of mystery rather than too much predictability into the design is always valuable (Kaplan et al. 1998).

\section{Design Style}

Historically, park design has evolved through a number of phases where different styles reflected the social, cultural and artistic movements of the times when they were created (Jellicoe 1995; Pregill and Volkmann 1999). These living works of art must be managed to retain their historic values whilst evolving in order to continue to fulfill contemporary functions. Thus, new park design can be inspired by historical precedents as well as by current artistic, architectural or cultural trends.

The use of trees in parks can range from deliberately architectural and formal, to informal and nature-like. Formal designs have been used for many centuries and are based on the arrangements of avenues, vistas and other elements laid out in strict geometrical patterns and using species of trees that also offer more formal possibilities. The arrangements may create symmetrical, balanced and formally harmonious aesthetic effects although it may be difficult always to accommodate the social, functional and ecological dimensions. Informal or deliberately naturalistic designs also have a very long pedigree (Von Buttlar 1989). They possibly lend themselves to a more eco- 


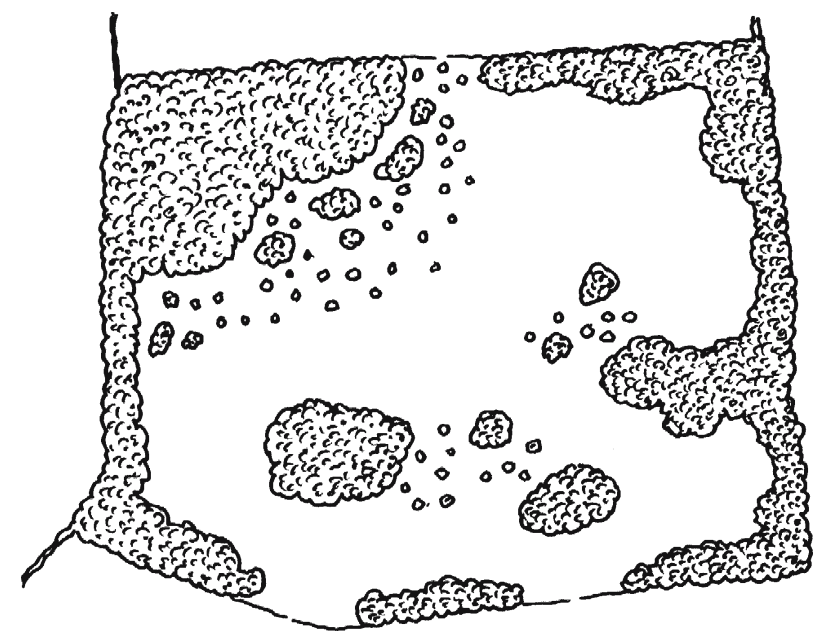

Fig. 6.12. This diagram represents the use of trees in a park (laid out in a very informal style) to create denser masses enclosing the main internal spaces. There are also larger or smaller clumps of trees and areas where the use of clumps and single trees blurs the mass/space distribution, providing different scales of space. The grass has been treated differently, being rougher and fuller of wild flowers in the area occupied by scattered trees, and more regularly mown in the main open areas. The large clumps block views, hide parts of the park and control vistas. They will coalesce in the view with other trees and the woodland to produce different degrees of enclosure or openness depending on the location of the viewer within the park (illustration: S. Bell)

logical approach where groups and clumps of trees together with shrubs and ground vegetation can be used to increase the biodiversity value. The spaces between trees may also offer more scope for a wider range of activities (Fig. 6.12).

Thus, there is a range of approaches, within which stylistic features can be selected as appropriate to suit the prevailing conditions. These considerations may also vary across the regions of Europe, since many of the traditions originate in different areas although they may have been copied elsewhere. Climatic variations may also influence the scope to use particular design elements, for example, in southern Europe the need for shade has led to park layouts where a high canopy of trees may provide a shade umbrella for activities taking place in the naturally colonnaded space beneath (Jellicoe and Jellicoe 1995; Pregill and Volkmann 1999). Conversely, some parks in northern Europe tend to favor dense clumps and belts to create sheltered places that also trap the sunshine. Such regional variations should not be overlooked.

Many of these park design principles may also be applied to the more intensively used sections of urban woodlands, since these can be quite park-like; in some places the park blends gradually into a wooded area.

\section{5 .3}

\section{Street Trees}

Earlier chapters in the book have presented the rationale for street trees to perform a range of functions such as shelter, shade or pollution mitigation. Their aesthetic value can 
also be very high, helping to soften hard and unattractive buildings or to add a further architectural dimension to the urban design. To carry out this function they need to be of a form and function that complements the built setting (Lyall 1991, Fig. 6.13).

However, it is worth noting that there are circumstances where the addition of trees to a street or square does not enhance the urban design. This might be the case in cities when the facades of the buildings and the overall composition of the urban spaces is so fine that any interference of the space or of vistas would be deleterious.

In other cases, trees have been purposefully incorporated into the urban design, where the choice of species, the natural tree architecture and its management by careful pruning are key factors to ensuring success. Trees such as plane (Platanus spp.) and lime (Tilia spp.) have frequently been used, but the aesthetic effect has not always been maximized as a result of poor pruning (see Chap. 15).

Aesthetic functions of street trees include the creation or continuation of vistas; establishing a more human scale at street level in cities where the built scale is very large; providing a visual contrast in form, texture, color and seasonal changes to the buildings or in contributing to the element of mystery by hiding and revealing city elements (Clouston and Stansfield 1981; St. Bodfan Gruffydd 1987; Bell 1991).

Regional variations in the use of street trees may arise mainly due to climatic differences and the available species that will thrive in different places. Plane and lime are surprisingly ubiquitous whilst others are more localized. Similar variations also occur as in parks, such as the need for shade in southern Europe compared to the need for shelter in the north west.

Fig. 6.13.

These street trees, in Freiburg, Germany, through careful choice of species or cultivar and appropriate crown shaping as they have developed, produce an effective sense of space that complements the urban form (photo: S. Bell)

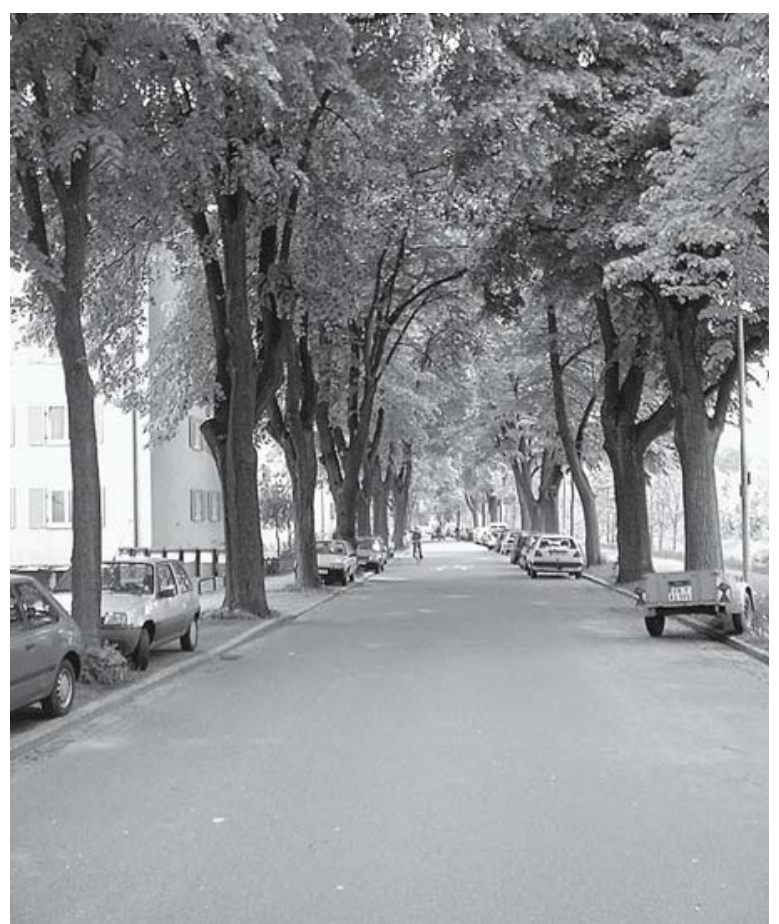




\section{6}

\section{Design Considerations}

This section takes each urban forest component, woods, parks and street trees, and considers a range of design aspects in greater detail. The emphasis lies in the presentation of a range of design considerations rather than a cookbook approach. Urban woodland design is achieved by the integration of a number of landscape elements in order to meet a set of design objectives and site constraints (Forestry Commission 1991). There is a well-established design process that should be followed, briefly described below.

\subsection{1 \\ Design Process}

The first task is to develop a design concept for the area under consideration, whether street, park or woodland, that defines the structure and layout in relation to the functional requirements such as expected use patterns by people on foot, bicycle, horse etc., location of access points, topography, protection of valuable biotopes, landscape character or sites of cultural or archaeological value. These objectives need to be established and it is more and more common for them to be derived from a community participation process. It is advisable to prepare a set of maps that describe these factors, which must be ascertained from a number of site surveys. Topography and site variation (soil type, nutrient status, drainage characteristics etc.) are frequently key determinants of tree species selection as well as dictating some of the likely use patterns and woodland ecosystem processes. Analysis of these factors will help determine the development of the design concept, together with the objectives.

The different elements within the design concept should, where necessary, define functional zones and describe the desired characteristics of these zones. A large site may contain more zones than a smaller one. There may also be linkages between the site and neighboring areas to be considered at the concept stage.

Under some circumstances, such as where a woodland or park is to be created on a site formerly used for industry or mineral extraction or in other manmade landscapes, it is possible that there is scope to design the landform itself. In these circumstances the microclimate variations able to be developed can have a significant effect on the outcome of the design. It may also be possible to introduce water features (Bell 1997b).

The design concept is then developed into a sketch design. The degree of detail and the scale of resolution will depend on the size and complexity of the area. Usually, a street planting scheme will be more detailed than the layout of a woodland.

Fig. 6.14a-j. This sequence of sketches demonstrates the design process appropriate for urban woodlands. A basic survey to collect all the site and context information is followed by a thorough analysis. From this is developed a design concept which coordinates the areas for different uses, path circulation systems and the woodland/trees/open space structure. This is developed into the sketch design which demonstrates the character and quality of the design. Perspective sketches help to convey the character to members of the public (illustration: S. Bell) 


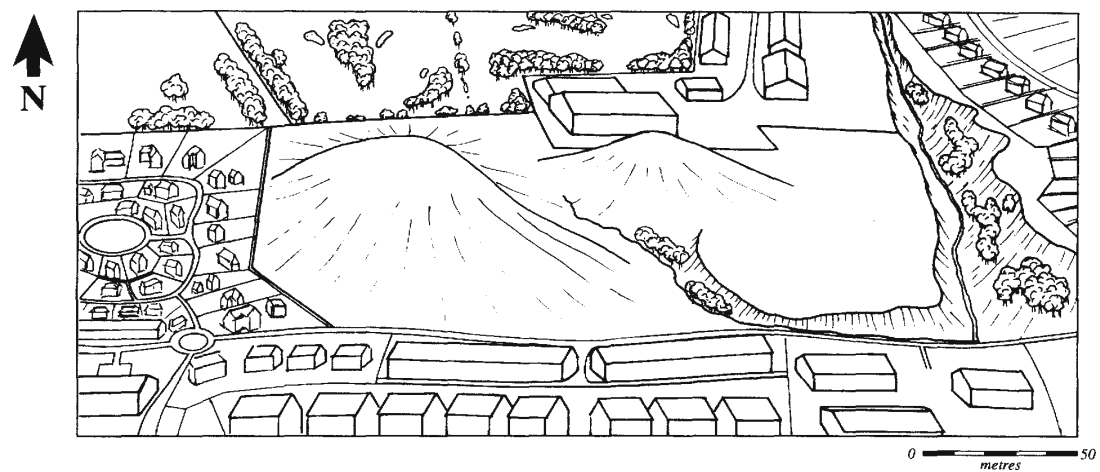

Fig. 6.14a. The existing landscape

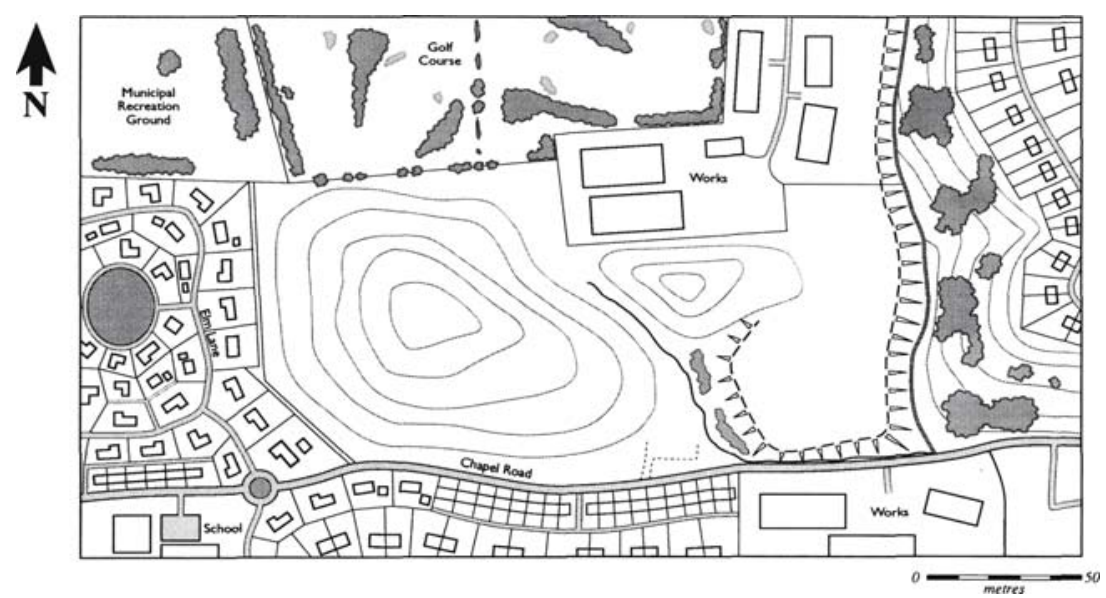

Fig. 6.14b. The existing landscape

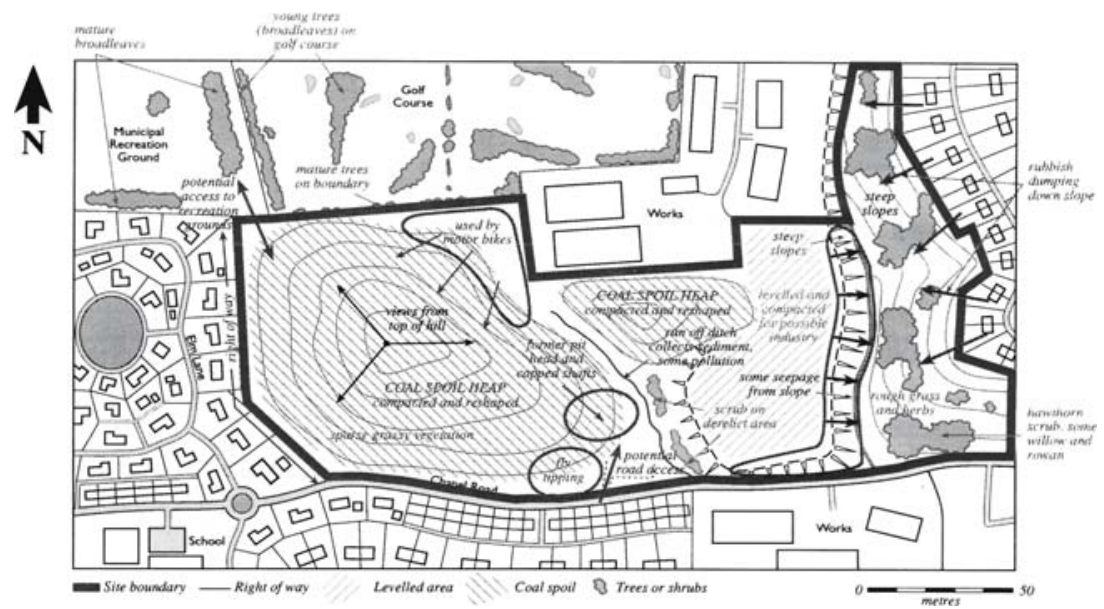

Fig. 6.14c. Survey 


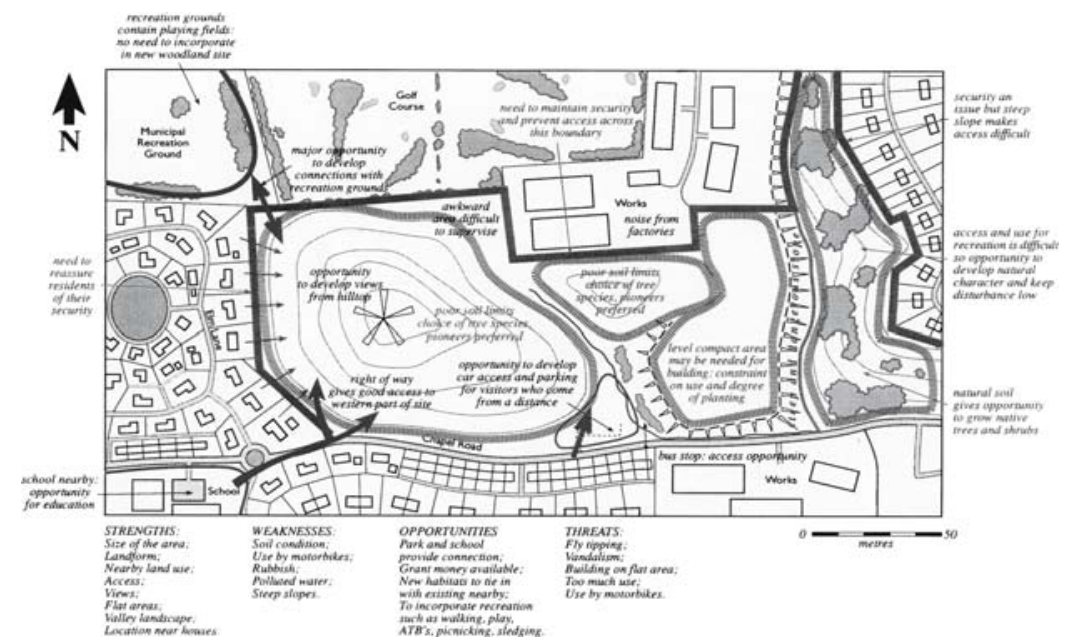

Fig. 6.14d. Site analysis

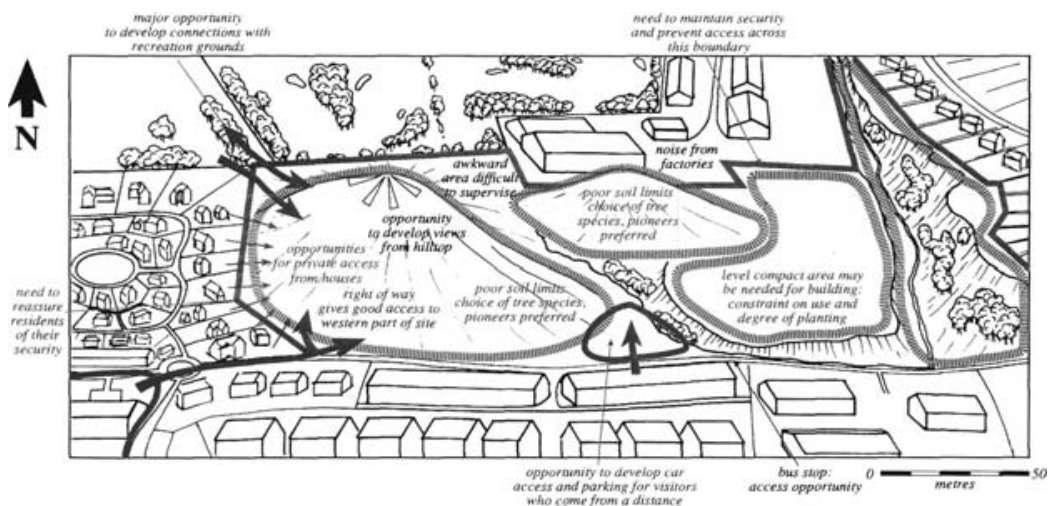

Fig. 6.14e. Site analysis

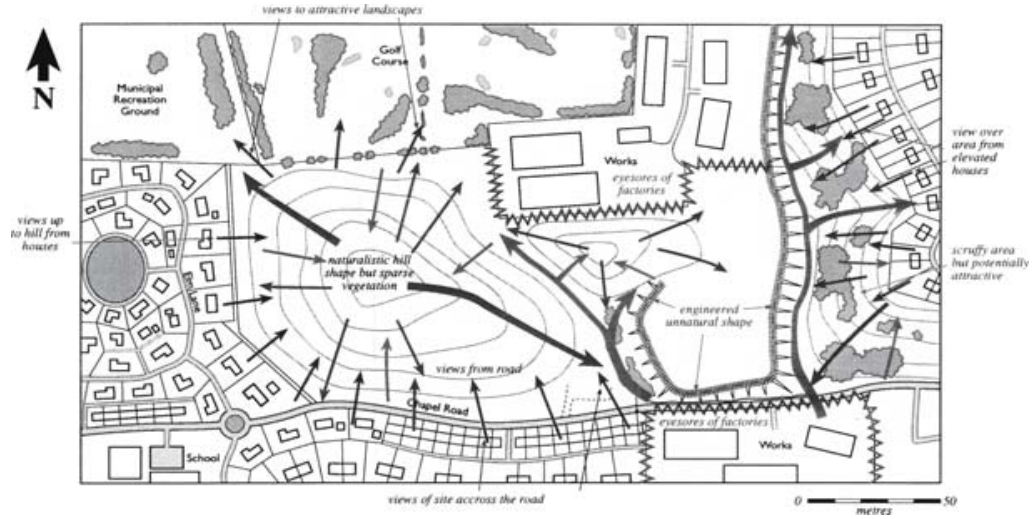

Fig. 6.14f. Visual appraisal 


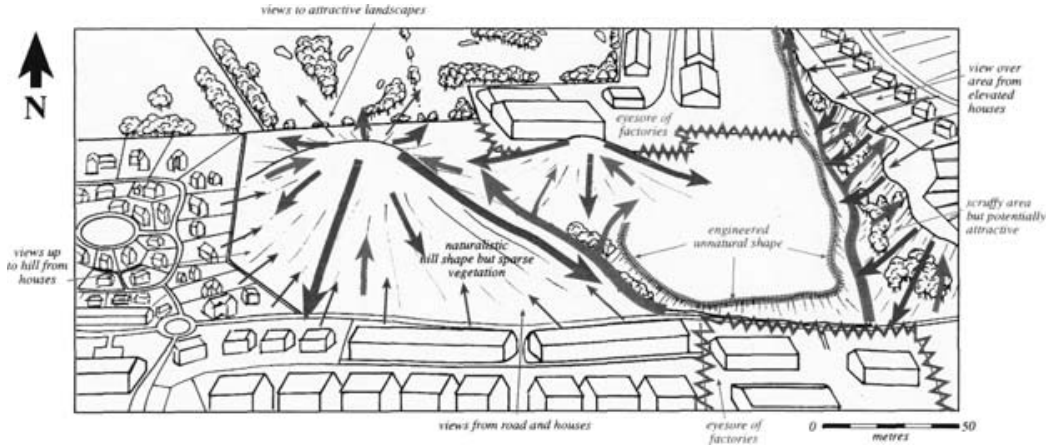

Fig. 6.14g. Visual appraisal

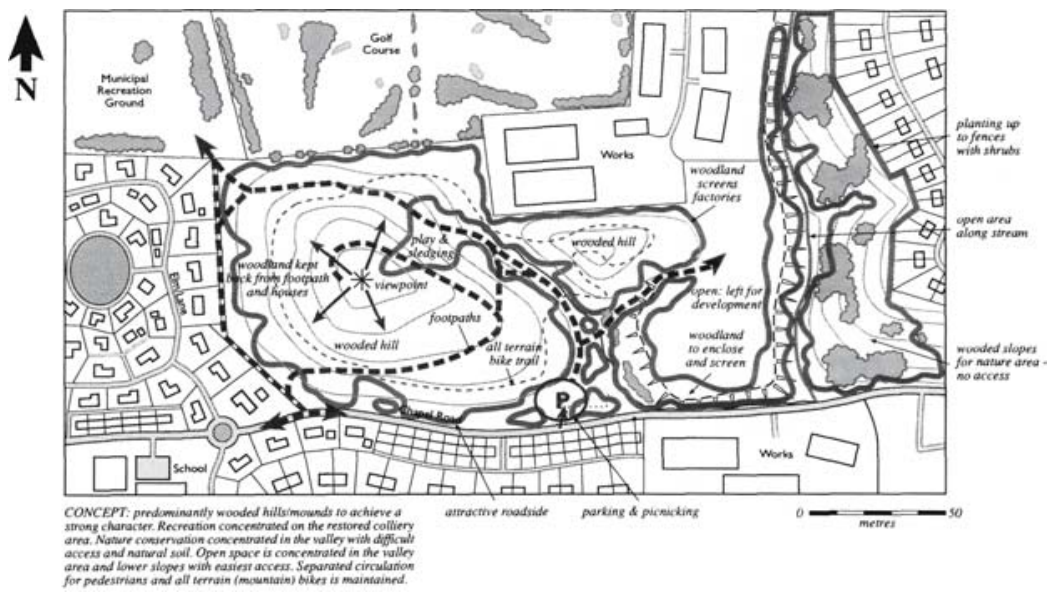

Fig. 6.14h. Concept

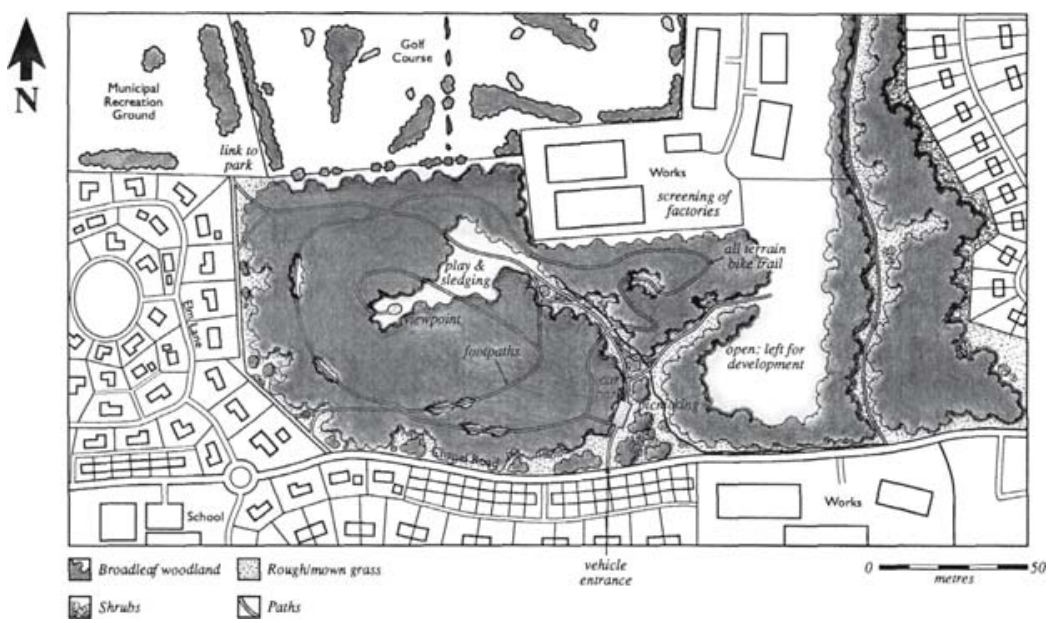

Fig. 6.14i. Sketch design 


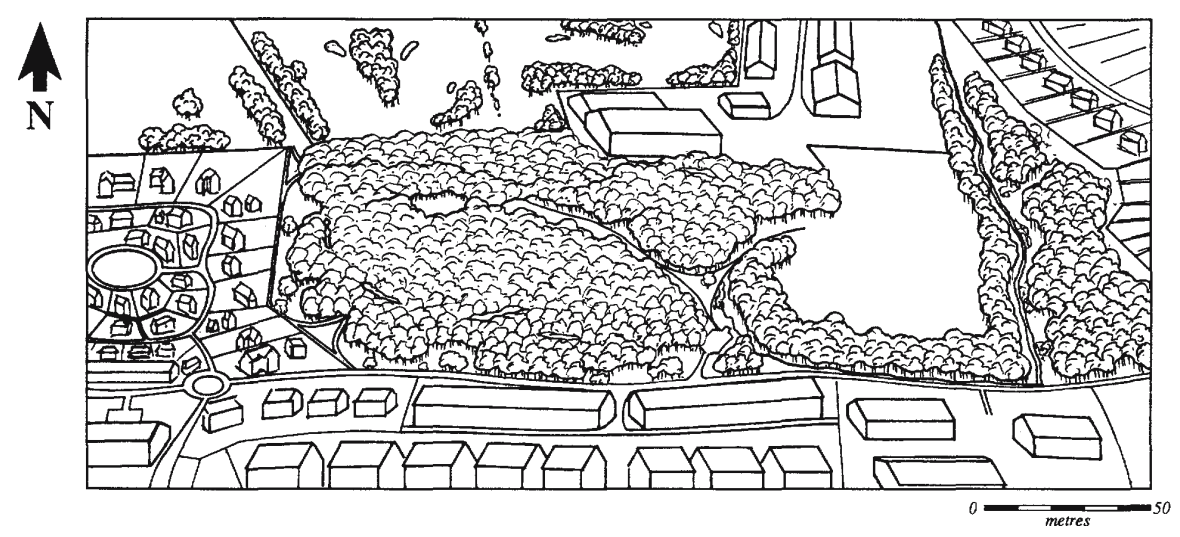

Fig. 6.14j. Sketch design

This generalized process may be applied as described or modified, depending on the circumstances (Fig. 6.14). Where communities are to be involved in design (see Chap. 8), this presents some interesting possibilities. Since most people are not designers, novel ways of generating ideas are needed. The use of art in various forms, model-making and processes such as 'Planning for Real' (Neighbourhood Initiatives Foundation 1999) can be used to help develop design ideas. If there is a deeper involvement by the community the design may never become detailed, remaining rather conceptual and only becoming finalized when actually implemented with the active participation of community members. The initial design in these circumstances may continue to evolve over time if the community is involved for a long period.

\section{6 .2 \\ Woodland Design}

Following the design concept the main task at sketch design is to determine the overall layout of the woodland in terms of spatial structure. This is the proportion and distribution of woodland versus open space and the degree of formality/naturalness in the design. Quite often, where there is topographic variation, this should reflect landform. For example, if woodland clothes the convexities whilst open areas are concentrated in hollows, this can not only develop a relationship between woodland and landform, but also tends to emphasize relief and increase the microclimatic benefits of sheltered hollows. Alternatively, woodland in valleys creates more shade and shelter whilst wide views can be obtained from open summits (Bell 1991; Forestry Commission 1991).

It is often a good idea to vary the overall proportion of woodland and open space across the site. Open areas can be concentrated around entrance points and in places where more intensive recreation takes place, whilst denser, wilder areas are located further away. This enables people to feel they are leaving the city further and further behind them as they move deeper into the woodland. Such a concept can be seen in the design of the Amsterdamse Bos (Oldenburger-Ebbers et al. 1998). 


\section{External Margins}

The next step in the design is to consider the external definition of the woodland. This depends on the nature of the adjacent land use. If housing areas abut the woodland it may be necessary to develop a transition zone to avoid too much shade being cast and to allow for concentrated pedestrian use (Forestry Commission 1991; Hodge 1995; Komulainen 1995). If the woodland adjoins fields the margin should allow an ecotone to develop and link to existing features such as hedges. Where topography is significant the design of the margin can help to reflect its character.

\section{Woodland Type and Species Choice}

Once the areas to be planted with trees have been defined it is necessary to consider the woodland types to be used. Species choice alone is not enough. The future structure and management should also be considered. It may also be appropriate to plant pioneer species, especially on difficult sites, rather than those that tend to appear later in forest succession. Regional variation may have significant influence. For example, in Scandinavia, pine and birch may not only be the pioneer species but also the canopy species throughout the life of the forest, whereas in central Europe, birch and pine may be succeeded by oak, beech or fir. It might also be appropriate to seed an area or let it develop naturally rather than planting it. This will depend on how quickly woodland cover is needed and how successful seeding or natural colonization is likely to be.

Woodland type also means the difference between, for example, high forest, where the trees grow naturally and form a canopy, or coppice where the trees are cut and sprout once more from the stump. There are important differences between these systems which may be traditionally used and have different biodiversity values (Peterken 1981; Forestry Commission 1991; Gustavsson and Ingelög 1994; see also Chap. 13). Wood pasture is another traditional type that may be considered useful. Woodland type can also include the number of species planted together and the vertical structure that develops. Sometimes a simple structure with an open canopy is desirable, such as that provided by beech, or in a more layered structure with overstorey, understorey and shrub layer. The species may be planted in an intimate mixture or as a series of groups of each species. Some woodland types tend to be found in the interior of woodland, others at the edges, owing to differences in light availability and shelter. Others are more generally dense or more open in structure, cast more shade or admit more light onto the forest floor (Stoffel 1994).

\section{Open Space}

Open space is usually an important component of urban woodlands. This may include non-woodland habitats, such as grassland, wetland, open water or heath, where ecological values are important. Recreational open spaces, such as paths, picnic areas, play spaces or viewpoints may also be needed (Forestry Commission 1991, Fig. 6.15). Finally, there may be open areas because of constraints to tree planting, such as electricity lines, gas pipelines, roads or areas of disturbed ground where tree growth is impossible. All such spaces should be designed to reflect the overall concept (Forestry Commission 1991; Lucas 1991; Komulainen 1995). 


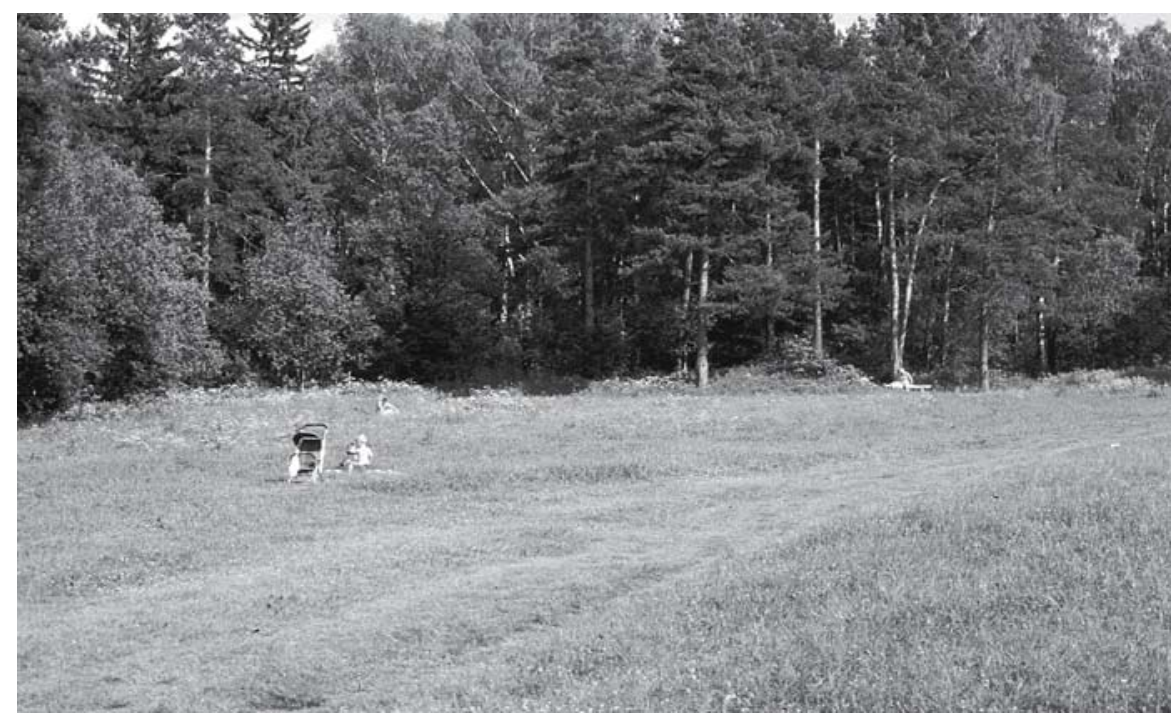

Fig. 6.15. Open space in part of Losiniy Ostrov (Elk Island) forest park in Moscow which fulfills many functions. It is an attractive open space for recreation, and it provides habitat diversity (photo: S. Bell)

If a natural character is desired, spaces should generally have an irregular, organic shape, for example, perhaps reflecting any local topographical variations and the vegetation, such as grass, should be managed accordingly, through a varied mowing regime, for example. Linear spaces should wind through the woodland (except where functional constraints apply) to create a sense of mystery (Bell 1998). Larger scale spaces can be sub-divided by additional planting of clumps and groups of trees to create more interest and to provide a greater visual carrying capacity.

\section{Paths and Circulation}

A significant aspect of most urban woodland design will be the system of paths for walkers, cyclists and horse riders. The patterns will depend on the size and shape of the woodland, the degree to which it is bounded by houses or residential areas, the number of access points and the terrain. In larger woods a network of separated paths for cyclists, walkers and horses is ideal, each network creating a series of loops (Bell 1997a). Where houses lie next to the woodland a path running alongside, just inside the wood, helps to collect the walkers from each house who may be able to gain access (Forestry Commission 1991; Komulainen 1995). Where there is a degree of fear or discomfort about venturing far into deep, gloomy woodland, the paths should offer a range of experiences. Those most frequented and which lead to major facilities should be more open, straighter and possibly lit to create a greater degree of comfort (Burgess 1995; Hodge 1995; Komulainen 1995; Fig. 6.16). Paths of all types should make the most of the terrain to provide interest, views and variety of landscape without causing difficulties to disabled or elderly people by being too steep or rough. Surfacing that is smooth and dry without being too urban in the use of materials is desirable (Bell 1997a). 
Fig. 6.16.

This diagram shows a woodland which has been zoned into 3 areas. Zone 1 has straight, wide, open, safe paths closest to the houses or where a direct route is needed. Zone 2 has winding paths, wide and easy to follow with many stretches running through open spaces. Zone 3 is a deeper woodland, with narrower, more twisting paths more usually running through closed canopy and less open. This provides those who enjoy solitude and wildness to get away from the busier parts of the woodland (illustration: S. Bell)

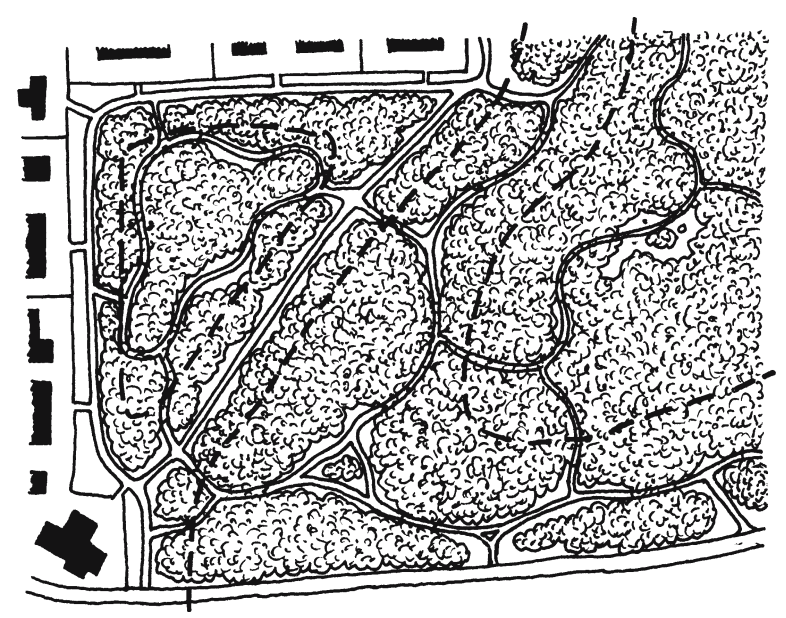

Edges

There are many edges along the outside of woodland or along internal open spaces. The structure of these edges can provide visual diversity and ecological value (Hodge 1995; Sarlov-Herlin and Fry 2000). Natural woodland edges usually grade from the tree canopy to the open area beyond through intermediate stages of clumps and groups of trees, patches of shrubs or younger trees, herbaceous plants and grass. These can provide added depth to views, help maintain a sense of mystery and provide variation throughout the seasons. They provide habitats for animals, birds and insects in conjunction with the denser woodland and open spaces, perhaps forming an ecotone. Conversely, it may be appropriate to develop a more open edge in order to provide views into the woodland canopy and to make it more accessible to people. Edge design follows two steps. Firstly there is the general shape of the line that defines the boundary between wooded and open areas, and secondly there is the structure and composition of the edge zone along that line (Lucas 1991, Fig. 6.17).

\section{Use of Natural Colonization}

Often, new woodland is established in areas that have been neglected in the recent past so that they may already possess a degree of scrubby woodland cover. This is usually the earliest colonization stage of abandoned land which will eventually become woodland, although at a slower pace than might be desirable. However, such natural colonization can be valuable since it presents a starting point for design, may save money and provide a degree of maturity to the area, wildlife habitat and a seed source for further expansion over time. In places where the site has been disturbed through industry and the soil is poor or non-existent, natural succession may be effective in helping soil forming processes and in creating conditions for the establishment of later successional tree species that would be unable to grow in the current condition of a site (Moffat and McNeil 1994; Hodge 1995). 

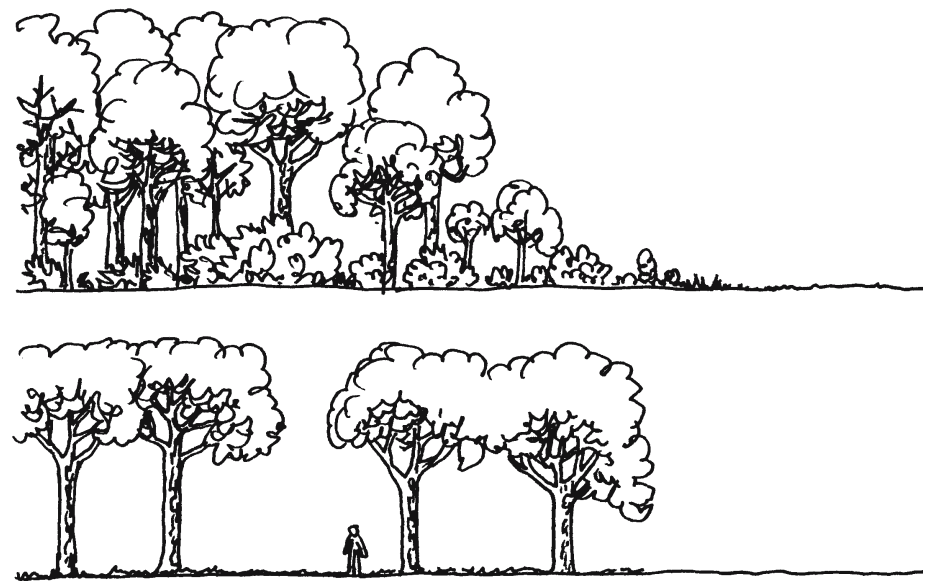

Fig. 6.17. In this pair of sketches example (a) shows a section through a natural woodland comprising many layers of trees, shrubs, ferns and herbaceous plants. At the outer edge the zone shows a tapering profile resembling that of a colonizing woodland. The ecotone structure as grassland gradually turns into woodland is ecologically valuable. Example (b) shows a simpler edge structure. The woodland has a single canopy and the ground layer is solely of grasses or herbaceous vegetation. The space flows into the woodland beneath the trees. While not as ecologically valuable, this creates a useful edge for recreational use and for enabling people to see beneath the trees, both into and out of the woodland (illustration: S. Bell)

\section{6 .3}

\section{Design Issues in Established Woodlands}

There are many examples where urban woodlands were originally wooded areas set within rural countryside but which, due to urban expansion, find themselves surrounded by houses. The original layout and management may have been for objectives very different to what is now required, so that considerable redesign may be necessary.

\section{Characteristics of Established Woodland}

Managed woodlands, whether of natural or planted origin, are frequently laid out or subdivided into rectangular compartments separated by straight linear openings or 'rides'. Fellings may have taken place, also to these rectilinear shapes, and the canopy of the woodland may be so dense that there is little understorey. The road or path network may follow the compartments and be designed for timber haulage. Thus management may need to be redirected to remove the geometric patterns over time, to develop a richer stand structure, to create open spaces where non exist and to insert a completely different path system.

\section{Future Vision}

The design concept for such woodlands should set out the desired future vision, such as changes to the layout, structure and composition, which woodland management is then directed towards through the adoption of silvicultural techniques, including cutting to reshape edges, create open spaces and planting to change species. The future 
vision might involve significant restructuring of the woodland over time (Forestry Commission 1992, Fig. 6.18).

\section{Open Space Creation}

Open space creation may be complicated by the presence of stumps, which may need to be removed, depending on the function of the space being created. Existing, straight linear open spaces may need to be obliterated through re-shaping and partial or complete planting to fill them in. Open spaces carved from existing woodland retain shelter and trap the sun from the start, but their edges are likely to appear raw. Thinning into the edge and then planting other species of trees and shrubs to create structure is likely to be needed (Lucas 1991).

Fig. 6.18.

These two diagrams show a woodland that has become surrounded by housing and industry. (a) shows the layout resulting from when the woodland was originally managed for wood production. It now needs to be redesigned to function better as a recreational resource and to provide more habitat diversity. (b) shows how it could be diversified, expanded and remodeled to meet a new set of objectives. A new path network has been developed. Open spaces have been cleared, parts of the forest have been felled and replanted to break up the geometric layout and to diversify the structure. Some of the old 'rides' have been filled in by planting (illustration: S. Bell)
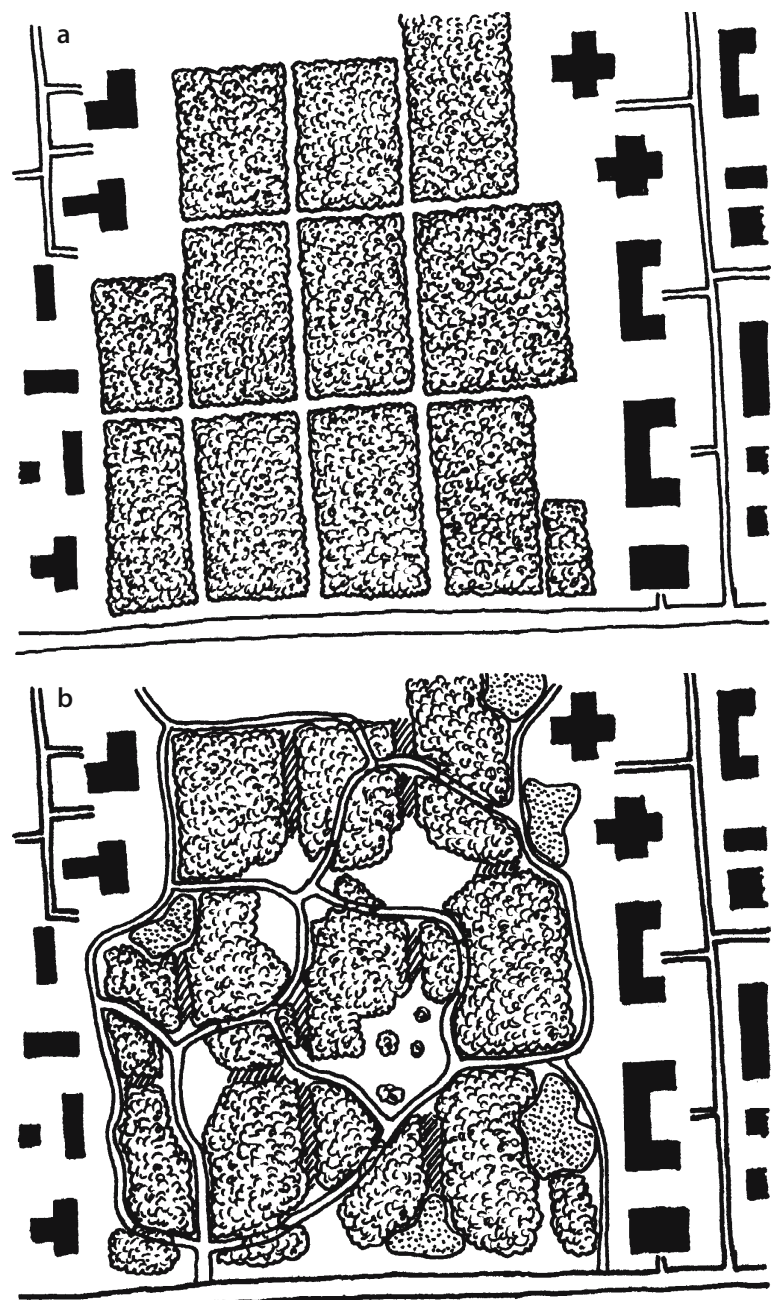


\section{Paths and Circulation}

While some of the existing roads and paths may be useable, it is likely to be necessary to develop a completely new path circulation system within woodland that has become part of the urban landscape. As soon as houses are built and people start to occupy them, they are likely to venture into the woodland. New path routes will start to appear which may be in undesirable locations. Once this pattern starts to develop it may be difficult to replace it, so it is advisable to consider the layout and development of the path system well before people start to use the woodland, if that is possible. Alternatively, adapting the initial pattern of desire lines, extending, linking and modifying it may be an equally if not more practical approach (Forestry Commission 1991; Bell 1997a).

\section{Woodland Restoration}

In urban fringe situations many woodlands may have been neglected by their owners and abused by people who realize that no one is particularly interested in them. If such woodlands are to be brought into positive use they must be restored. This not only includes cleaning them up, but regenerating the tree cover, installing or repairing paths and other facilities and possibly considerable redesign of layout, structure and composition, especially open spaces.

\subsection{4}

\section{Parks and Urban Forest Design}

The design principles for parks where trees, tree clumps or wooded areas are to form a significant element are little different from that of woodland. The spatial layout, functional planning and access provision all need to be considered. However, the spatial qualities of trees in parks may present a wider range of opportunities (Fig. 6.19).

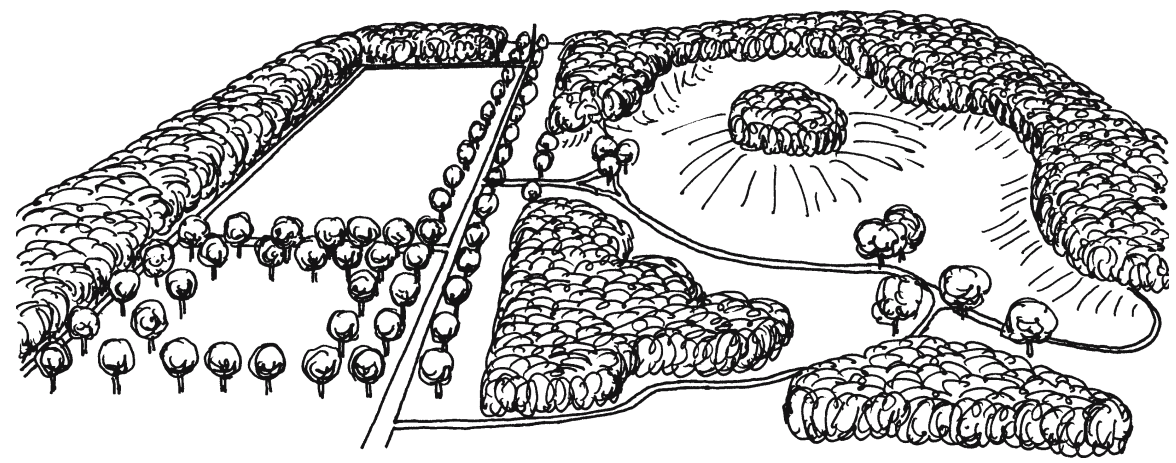

Fig. 6.19. This sketch shows the different design effects possible depending on how trees are deployed to create space, mass, enclosure and view control. To the left is a formal design, where a geometric grid has been used to create a very calm, static and controlled result, symmetrically balanced, axial and emphasizing the single point perspective. The design on the right is based on organic shapes with greater use of interlock, coalescence and asymmetric balance. By planting on the knolls, the enclosing effect has been intensified. The result produces a greater sense of mystery and is more relaxing (illustration: S. Bell) 
Single trees in large open spaces act as focal points and an opportunity to display a specimen of beauty, perhaps a spreading form, large size or brilliant flowers, foliage or branch form. Open grown trees develop their crowns in different ways to woodland trees and can be used to great effect. They may also be pruned, trained or varieties may be chosen with particular crown forms (St. Bodfan Gruffydd 1987; Clouston 1990).

Clumps or groups of trees present masses in space, but also contain open volumes within them. The arrangement of the trees, whether there is an open, simple canopy or an understorey can make a compositional difference. Usually, the crowns of tree clumps grow together to present a solid mass. The space beneath, if the floor is clean, provides shelter and shade with views out all around. Trees arranged in straight rows at equal intervals create a formal atmosphere while those in more irregular spacing feel more relaxed and natural. Clumps can be used to emphasize topographical features by, for example, placing them on a knoll (Forestry Commission 1992).

Larger areas of woodland in a park should be considered much like woodland design described in the earlier section. However, the woodland, the clumps and the single trees should be considered as a compositional whole, screening or focusing views, balancing each other and enclosing or opening space.

Avenues and rows of trees may be used as other devices to compose space, focus views, emphasize spatial patterns or act as elements of continuation from street tree patterns (Clouston 1990). They generally formalize the composition and can also be used to relate to architectural elements in the landscape.

Larger clumps or patches of woodland can provide valuable habitat and can be developed with a more complex structure and composition. Edges and transitions from trees to the larger scale open spaces can range from abrupt and formal to gradual and informal (Forestry Commission 1991; Gustavsson and Ingelög 1994). The latter can also be a richer habitat.

Species choice for park trees can include a wide range. Parks are usually designed and laid out with amenity and recreation as a major objective and there are few natural park-like landscapes in Europe, except in some Mediterranean areas. Thus it is generally considered more acceptable to include a higher proportion of trees that are chosen for their aesthetic qualities of form, flowers, colors, branching habits and tolerance of urban environments (Clouston 1990).

\subsection{5}

\section{Street Trees and Urban Forest Design}

Street trees, those found in squares, streets and other public urban spaces, can be used in various ways. It is useful to consider what spatial qualities are desirable and to choose species with appropriate growth habits. For example, trees with large spreading crowns casting a wide zone of shade can be used in public spaces in hotter countries. These enable the outdoors to be used more than indoors, and life can take place on the street. Alternatively, trees with deeper, denser but narrower crowns, can provide shelter, espe- 
cially where the city buildings accentuate the wind in colder northern climates. These functional characteristics also have an effect in creating space beneath a large canopy or enclosing it with rows of denser trees (St. Bodfan Gruffydd 1987; Clouston 1990; Lyall 1991).

Tree form: There is a huge range of different tree forms that present various textures or colors and provide different degrees of light and shade. Many also need careful pruning and management to gain the maximum effect. The scale of the street or urban open space should dictate the appropriate size of tree. Small spaces, narrow streets and low buildings can be dwarfed by trees that grow too big, while small trees look out of proportion in large scale spaces. It is possible, though, to use them to reduce spaces and buildings of a large, inhuman scale, down to more appropriate proportions as an integral part of urban design.

Trees can relate to built form in a variety of ways. The natural, graceful shapes of trees in contrast to severe, simple geometric forms of some modern buildings can make a fine composition. Trees can also extend the built form, such as rows of trees continuing a line of columns or an avenue where the tree crowns meet and form a natural vault continuing a natural colonnade or covered aisle. Trees of vertical, narrow form can be used to complement buildings of more horizontal emphasis. It is important in all these cases to choose trees that not only grow in the climate and soil conditions but also provide the correct architectural qualities (St. Bodfan Gruffydd 1987; Clouston 1990; Lyall 1991).

The architectural use of trees finds its greatest expression where they dominate the streetscape. Here, trees are used to create or to unify the urban landscape and are deliberately brought in to counteract problems of the built form around them. This may be because the buildings have little architectural merit and lack unity or because of the over-large scale combined with low variety, so that the trees provide an alternative, more powerful structure. The following list described some of the main ways that trees can be used.

Avenues should be used with care in urban areas, and are unlikely to be suitable within city centre core areas. Generally, streets are likely to be too narrow, and the need for an avenue to lead from something or somewhere to the equivalent can rarely be achieved. They can however be useful to define important routes into and out of the city core, add character to such areas and add to the establishment of a strategic hierarchy of route-ways. Normally, an avenue of trees should be of the same species, planted at the same time and to the same specification to ensure an overall conformity of appearance. Canopy height should be considered in terms of whether it is necessary to give vehicles or pedestrians clearance underneath.

A single line of trees is far more likely to be accommodated within a city centre core area than an avenue, as it takes up far less valuable space. Due consideration should be given to the aspect of the trees (i.e. either on the sunny side or the shady side of the street, depending on species or desired design effect). As with avenues, lines of trees should be of the same species, planted at the same time and to the same specification to achieve design uniformity. The use of a single line of trees of different species could be considered, but care should be taken to avoid compromising the strength and design simplicity of a mono-species approach. Often the only element of continuity that 
can be established in an area of mixed uses, architectural styles and variable scales is a line of mono-species trees.

The distance between the ground plane and the base of the canopy is crucial. Not only should this be designed to accommodate easy pedestrian movement, but also to allow unimpeded views of the fascia boards of adjacent commercial or retail premises. Streets suitable for single lines of trees could be considered as 'Key Streets', where a (long-term) program of public utility rationalization could be put in place so that trees occupy one side of the street, with the services and utilities located in a common service trench on the other.

Block: This would normally consist of four trees, or maybe four small groups of trees, sited to highlight or articulate an important point, an intersection for example, or perhaps where a light rail system traverses a trafficked road or a pedestrian route. Normally such trees would be planted as large specimens, to create an immediate 'presence' and also to accommodate movement (pedestrian or vehicular) underneath.

A grid of trees can be large or small, and be of variable spacing dependent upon the end-use of the area beneath. They can be used in pedestrian areas to add interest; can articulate car parks wonderfully; or can be used simply to define a flexible urban public space that could accommodate a wide range of uses on different days - a market, casual car park, seating and tables for adjacent cafés, etc.

Small groups: These can be used where a more informal planting layout is required, and can be associated with a wide range of different treatments, including detailed paving design, raised beds, at-grade beds, other planting schemes and seating. The informality of a small group allows more informal tree species to be chosen and, depending upon the location, may not require a canopy height which allows pedestrian movement to take place underneath.

Trained trees are greatly under-used in urban areas. They have great potential to help with articulating space in places where more traditional tree planting would not fit. There are a number of different types of trained tree, but pleached trees would seem to offer the most potential. Pollarding may, in certain locations also be a valuable tech-

Fig. 6.20.

In this diagram the use of trees to break down the scale of a modern urban street is demonstrated. In (a) there is nothing to give a transition between the human size and that of the large scale, simple buildings. This dwarfs the person and can lead to discomfort. The use of trees, while themselves dwarfed by the buildings, creates an intermediate, more human scaled space at street level (illustration: S. Bell)
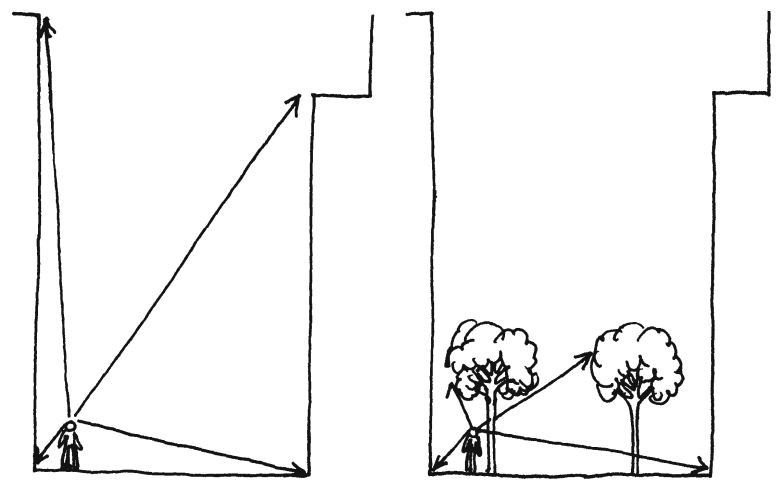
nique, but this should not be confused with annually pruning of all or most of a trees branches as a form of management.

Landmark: These trees should create a significant impact in their own right. They might compliment significant buildings or spaces, be key focal points, or articulate space. They would be 'characters' either in terms of size or appearance, but need not always be of large proportions, as landmark trees could be found in relatively small, intimate spaces.

Street trees can also be used, particularly in wider avenues or boulevards, to sub-divide the linear space and to separate pedestrians from traffic. In this way the trees define different use zones as well as helping to create visually and physically separate spaces. Wide pavements separated from cars by a strip down which trees are planted make a space that focuses attention on the pedestrian areas and building facades (Fig. 6.20).

In the context of the more important route corridors such as along the edges of urban motorways or railway lines, trees need to be planted in greater numbers and more densely, in order to create visual separation even if the noise abatement value is limited. These linear strips should be unified with the rest of the street tree structure while at the same time acting as wildlife corridors leading from urban edge to city centre.

Where there are streets that follow canal, river or lake edges, trees planted along them can provide a link between land and water, providing contrast and unity at the same time. Tree species associated with water, such as poplars and willows, might be favored in these circumstances. Examples of this type of planting can be found in Bruges or Amsterdam.

\section{7}

\section{Conclusions}

This chapter has explored a number of aspects relating to the design of the urban forest. Most opportunities to affect the urban landscape lie in the series of public spaces that form the glue holding the built environment together and provide the conduits for the movement of people and areas for outdoor city life and social intercourse. This is not to overlook the value of the contribution made by trees in gardens and other private or commercial areas. The urban forest, in occupying this network of public spaces, can form a matrix, unifying all those spaces with each other and with the built environment. Each constituent space should have its own character and reflect its context, whether peri-urban woodland, city park, small-scale park or garden, major or minor movement corridor, city centre street or public square.

The designer's job is to integrate each component into a unified whole, achieving a balance between each of the dimensions described earlier in the chapter - the social, the experiential, the functional and the ecological. In a peri-urban woodland the ecological dimension may take precedence, although the other three remain important. The design material is the 3-dimensional mass created by trees singly, in a group or en masse in larger volumes. Spaces inside, under, between and within these masses of trees provide an infinite variety of possibilities, set within the framework provided by the built environment.

Many cities are already richly endowed with components of the urban forest. The challenge is to take this rich legacy, protect and manage it but also extend and add to it 
to create a future legacy to pass on to the next generation of urban citizens. The existing examples, to be found all over Europe, may provide inspiration but it is also vital to develop new approaches and to apply novel solutions to meet the challenges of today.

\section{What Are These Design Challenges?}

The major challenge is to contribute to the development of sustainable cities by using trees in the best ways to enhance water and air quality, reduce energy costs and at the same time provide human and wildlife habitats.

Another challenge is to preserve and manage the existing resource while adapting it to present and future needs. This can mean some tough design decisions when trees are old, diseased or damaged yet highly valued by the public.

A third challenge is to make the urban forest accessible to everyone, no matter where they live, their age, ethnicity or economic situation. This means matching the urban tree resource to the places where people live and work so that the urban forest can become part of every citizens life, should they choose to take up the opportunity offered to them.

Good urban forests do not occur by accident; some form of planning and design is needed to ensure that woodlands, parks and street trees enhance the cityscape and provide settings that encourage people to use them as part of their everyday life. They must be welcoming, safe, attractive and conducive to a wide range of uses.

\section{References}

Baines C, Smart J (1991) A guide to habitat creation. London Ecology Unit, London

Bell S (1991) Elements of visual design in the landscape. E \& FN Spon, London

Bell S (1994) Design issues and objectives. In: Sangster M, Chambers K (eds) Proceedings of the $3^{\text {rd }}$ International Conference on Urban Forestry, Manchester. Forestry Commission, Edinburgh, pp 113-122

Bell S (1997a) Design for outdoor recreation. E \& FN Spon, London

Bell S (1997b) The importance of design in the aftercare of disturbed land. In: Moffat AJ (ed) The after use of disturbed land for forestry. Forestry Commission Technical Paper 22. Forestry Commission, Edinburgh, pp 21-25

Bell S (1998) The landscape value of farm woodlands. Information Note 13. Forestry Commission, Edinburgh

Bell S (1999a) Landscape: pattern, perception and process. E \& FN Spon, London

Bell S (1999b) Urban woodland: a vision for greener towns and cities. In: Collins KD (ed) Proceedings of the $3^{\text {rd }}$ National Conference on Urban Forests, Galway, Ireland. Tree Council of Ireland, Dublin, pp 57-60

Bell S (1999c) Tranquility mapping as an aid to forest planning. Information Note 16. Forestry Commission, Edinburgh

Berleant A (1992) The aesthetics of environment. Temple University Press, Philadelphia

Bosch JW, Slabbers S (eds) (1993) Grote bossen bij Europese steden (Large forests near European cities). IKC NBLF, Ministerie van Landbouw, Natuurbeheer en Visserij, Wageningen, (in Dutch)

Bradshaw A, Hunt B, Walmesley T (1995) Trees in the urban landscape. E \& FN Spon, London

Burgess J (1995) Growing in confidence. Counryside Commission, Cheltenham

Clouston B (ed) (1990) Landscape design with plants. $2^{\text {nd }}$ ed. Heinemann Newnes, London

Clouston B, Stansfield K (eds) (1981) Trees in towns. Architectural Press, London

Coles L, Bussey S (2000) Urban forest landscape in the UK - progressing the social agenda. Landscape Urban Plan 52:181-188

Fairbrother N (1970) New lives, new landscapes. Architectural Press, London 
Forestry Commission (1991) Community woodland design guidelines. HMSO, London

Forestry Commission (1992) Lowland landscape design guidelines, HMSO, London

Forman RTT (1995) Land mosaics. Cambridge University Press, Cambridge

Forman RTT, Godron M (1986) Landscape ecology. Wiley, New York NY

Gustavsson R (2002) Afforestation in and near urban areas. In: Randrup TB, Konijnendijk CC, Christophersen T, Nilsson K (eds) COST Action E12: urban forests and trees. Proceedings No. 1. Office for Official Publications of the European Communities, Luxembourg, pp 286-314

Gustavsson R, Ingelög T (1994) Det nya landskapet (The new landscape). Skogstyrelsen, Jönköping, (in Swedish)

Harrison RP (1992) Forests: the shadow of civilisation. University of Chicago Press, Chicago IL

Hodge SJ (1995) Creating and managing woodlands around towns. Forestry Commission Handbook 11. HMSO, London

Jellicoe G, Jellicoe S (1995) The landscape of man, revised ed. Thames and Hudson, London

Kaplan R, Kaplan S, Ryan RL (1998) With people in mind. Island Press, Washington DC

Komulainen M (1995) Taajamametsien (Urban forestry). Kustannusosakeyhtiö Metsälehti, Jyväskylä, (in Finnish)

Laurie IC (1979) Nature in cities. John Wiley and Sons, Chichester

Lucas OWR (1991) The design of forest landscapes. Oxford University Press, Oxford

Lyall S (1991) Designing the new landscape. Thames and Hudson, London

Marsh S (1991) Nature conservation in a community forest; guidelines for Thames Chase. Countryside Commission, Cheltenham

McHarg I (1969) Design with nature. Natural History Press, New York NY

Ministerie van VROM (1991) Vierde Nota over de Ruimtelijke Ordening Extra, deel III: Kabinetsstandpunt (Fourth Note on Spatial Planning Extra, part III: cabinet position). Ministerie van Volshuisvesting, Ruimtelijke Ordening en Milieu, Den Haag, (in Dutch)

Moffat A, McNeil J (1994) Reclaiming disturbed land to forestry. Forestry Commission Bulletin 110. HMSO, London

Neighbourhood Initiatives Foundation (1999) 'Planning for Real' ${ }^{\circledR}$. The Neighbourhood Initiatives Foundation, Telford

Oldenburger-Ebbers CS, Backer AM, Blok E (1998) Gids voor de Nederlandse tuin- en landschapsarchitectuur, deel West (Guide for the Dutch garden and landscape architecture, part West). De Hef, Rotterdam, (in Dutch)

Peterken G (1981) Woodland conservation and management. Chapman and Hall, London

Pregill P, Volkmann N (1999) Landscapes in history. John Wiley \& Sons, New York

Sarlov-Herlin IL, Fry GLA (2000) Dispersal of woody plants in forest edges and hedgerows in a Southern Swedish agricultural area: the role of site and landscape structure. Landscape Ecology 15(3):229-242

Simms S, Hislop M (1999) An examination of forest recreation policy in four European forest cultures focusing on the impact on silvicultural practice. Forestry Commission, Roslin, unpublished paper

Schuit S, Hajonides T (1991) Waar door de wouden... Bosontwerp en sociale veiligheid (Where through the woods... Forest design and social security). Buro Zijaanzicht for Directie Bos- en Landschapsbouw Utrecht, Wageningen, (in Dutch)

Sievänen T (ed) (2001) Luonnon virkistyskaytto 2000 (Outdoor recreation 2000). METLA, Helsinki, (in Finnish)

St. Bodfan Gruffydd J (1987) Tree form, size and colour. E \& FN Spon, London

Stoffel W (1994) Ontwerpen met het 'levende' bos (Designing with the 'living' forest). IKC NBLF, Ministerie van Landbouw, Natuurbeheer en Visserij, Wageningen, (in Dutch)

Tummers LJM, Tummers-Zuurmond JM (1997) Het land in de stad, de stedebouw van de grote agglomeratie (The land in the city; the city planning of the large agglomeration). THOT, Bussum, (in Dutch)

Von Buttlar A (1989). Der Landschaftsgarten: Gartenkunst des Klassizismus und der Romantik (The landscape garden: garden art from classicism and romanticism). DuMont, Köln, (in German)

Ward Thompson CWT, Aspinall P, Bell S, Findlay C (2002) Local open space and social inclusion: case studies of use and abuse of woodlands in central Scotland. OPENspace research centre, Edinburg 